\title{
The Effect of Employment Protection on Teacher Effort ${ }^{*}$
}

\author{
Brian A. Jacob \\ University of Michigan \& NBER
}

March 2012

\begin{abstract}
$\underline{\text { Abstract }}$
This paper studies the effect of employment protection on teacher effort and student achievement. In 2004, the Chicago Public Schools (CPS) and Chicago Teachers Union (CTU) signed a new collective bargaining agreement that gave principals the flexibility to dismiss probationary teachers (defined as those with less than five years of experience) for any reason, and without the elaborate documentation and hearing process typical in many large, urban school districts. Results suggest that the policy reduced annual teacher absences by roughly 10 percent and reduced the prevalence of teachers with 15 or more annual absences by 25 percent. The majority of the effect was due to changes in the composition of teachers in the district, although there is evidence of modest incentive effects for young untenured teachers.
\end{abstract}

\footnotetext{
${ }^{*}$ Generous financial support was provided by the William T. Grant Foundation. Thanks to Nancy Slavin, Raquel Saucedo, Art Kim, Joshua Garcia, Lauren McClellan, Amy Nowell, Dan Bugler, Ascencion Juarez and Angela Alonzo at the Chicago Public Schools, and to Tim Daly and Andy Sokatch at The New Teacher Project. Thanks to Elias Walsh, Joshua Hyman, Michael Gelman and Stephanie Rennane for excellent research assistance. Thanks to Kerwin Charles, John DiNardo, Robin Jacob, Lars Lefgren, Ioana Marinescu, Jonah Rockoff, Kevin Stange and many seminar participants for helpful comments and suggestions. Any errors are my own.
} 
"What kind of person could you get to run a small business if you told them that when they came in they couldn't get rid of people that they thought weren't any good?”

Apple Cofounder and CEO Steve Jobs, referring to the importance of staffing in public schools

\section{Introduction}

Economists have long argued that the lack of incentives in most public school systems substantially reduces student performance and increases the cost of education (Hanushek 1994; Hoxby 2003). Teacher employment and compensation policy is one of the most commonly cited instances of weak incentives leading to suboptimal outcomes. As reflected in the quote by Steve Jobs, labor contracts in most public school districts make it extremely difficult for administrators to dismiss teachers for cause. In New York City, for example, only about 50 out of roughly 75,000 teachers were dismissed for performance-related reasons in recent years. ${ }^{1}$

Recent "value-added” studies on teacher effectiveness have documented substantial variation in teacher effectiveness both within and between schools (e.g., Steven G. Rivkin, et al., 2005, Jonah E. Rockoff, 2004), intensifying the scrutiny of policies related to teacher hiring, promotion and compensation. ${ }^{2}$ Many school districts have begun to experiment with pay-forperformance plans, and there is increasing discussion of ways to change the teacher tenure system that would provide school administrators with greater flexibility over staffing. The

\footnotetext{
${ }^{1}$ Personal communication with Jonah Rockoff, February 19, 2008. While there are no nationally collected data on firing per se, the Bureau of Labor Statistics (BLS) does collect statistics on separations. According to recent report, the separation rate (layoffs and discharges) in November 2011 was 1.3 percent overall, 0.5 percent in the education service industry and 0.7 percent in the health and social assistance industry, and 2.3 in the professional and business services industry (BLS 2012)

${ }^{2}$ In general, variance estimates indicate that a student with a teacher one standard deviation above the mean would score roughly .2 student-level standard deviations higher on standardized math exams. The magnitude of this effect is roughly equivalent to the effect of class size reduction found in the highly acclaimed Tennessee STAR class size reduction experiment, although it should be noted that recent evidence suggests that the impact of having a particularly effective (or ineffective) teacher as measured by value-added fades out considerably within a year or two (see, for example, Jacob et al. 2010).
} 
Chancellor of the Washington, D.C. public schools, for example, recently proposed to substitute higher teacher salaries in exchange for a suspension of tenure privileges for one year (Haynes 2008).

And, yet, there is little empirical evidence on whether such incentives will change teacher behavior or improve student achievement. Evidence on merit pay is mixed (Springer and Podgursky 2008, Lavy 2008). There is some evidence that school accountability can improve student achievement, but these policies (including the federal No Child Left Behind program) provide few direct incentives for teachers as they do not change teacher compensation and teachers' job security is still (mostly) guaranteed by collective bargaining agreements. To the best of my knowledge, there is no direct evidence whatsoever on whether policies such as those commonly cited by observers such as Steve Jobs - namely those that reduce employment protections for teachers - will actually improve productivity. Indeed, several recent reports document that existing teacher contracts in many large urban school districts actually provide considerably more flexibility than is commonly believed and yet administrators rarely take advantage of such flexibility (Ballou 2000, Hess and Loup 2008, Price 2009).

In this paper, I take advantage of a unique policy change to examine how the reduction of employment protection for teachers impacts teacher effort and student achievement. In 2004, the Chicago Public Schools (CPS) and Chicago Teachers Union (CTU) signed a new collective bargaining agreement that gave principals the flexibility to dismiss probationary teachers for any reason, and without the documentation and hearing process that is typically required for teacher dismissals. In practice, this dramatically reduced the costs associated with firing young teachers in the district. ${ }^{3}$

\footnotetext{
${ }^{3}$ An informal survey of the 10 largest school districts in the country revealed that principals in these districts do not have the flexibility that Chicago principals were recently granted.
} 
To identify the impact of the policy on teacher effort, I utilize a difference-in-difference estimator that compares changes in teacher absences before and after the policy for probationary versus tenured teachers. As described in more detail below, employee absences have been used in studies of employment protection in other industries, and provide a particularly good proxy for productivity in education.

Results suggest that the policy reduced annual teacher absences by roughly 10 percent and reduced the prevalence of teachers with 15 or more annual absences by 25 percent. The majority of the effect was due to changes in the composition of teachers in the district, although there is evidence of modest incentive effects for younger untenured teachers. The effects were strongest among teachers in elementary schools and teachers with high predicted absences.

While student achievement is a more direct measure of teacher productivity, it is not possible to link students to teachers in Chicago over the relevant time period, making it impossible to calculate individual teacher productivity measures. ${ }^{4}$ For this reason, I rely on school-year data to examine the impact of the policy change on student achievement, comparing within-school changes in student achievement over time between schools with higher versus lower fractions of probationary teachers at the time the policy was implemented. ${ }^{5}$ I find that the policy increased student achievement in low-achieving elementary schools, although this result is somewhat sensitive and I do not find evidence of achievement effects in other schools. Back-ofthe-envelope calculations indicate that the effects on teacher absences likely explain only a small

\footnotetext{
${ }^{4}$ Moreover, even in the best circumstance, a measure of teacher productivity based on student achievement would not be available for the large fraction of teachers in grades and subjects where students do not take standardized exams.

${ }^{5}$ While average teacher experience in a school is correlated with student achievement and socioeconomic status, I show that there is substantial variation in the fraction of probationary teachers across observationally similar schools. Moreover, by examining within-school changes over time, I can control for any unobservable timeinvariant characteristics of schools that might be associated with initial teacher experience levels and subsequent student achievement (e.g., a particularly dangerous neighborhood, aging school facilities).
} 
part of the achievement effects, suggesting that the policy may have impacted teacher behavior in other ways as well.

This study makes several important contributions. Perhaps most importantly, the findings presented here have important implications for current education policy debates. Specifically, the decline in teacher absenteeism following the introduction of the policy suggests that changes in teacher contract provisions may improve student achievement. In addition, this analysis contributes to the economic literature on employment protection more generally. To the best of my knowledge, it is one of the few empirical studies of the impact of employment protection on worker effort, and the only study to directly examine this issue in the public sector. By using detailed administrative data that provides employee- and firm-level productivity measures, and exploiting a plausibly exogenous source of variation in employment protection, the analysis here provides compelling evidence on these important issues.

The remainder of the paper proceeds as follows. Section 2 reviews the prior literature on employment protection and teacher incentives. Section 3 provides background on teacher dismissals in the Chicago Public Schools, and outlines a conceptual framework to help understand the ways in which the policy might influence teacher effort and school productivity. Sections 4 and 5 describe the empirical strategy and data respectively. Section 6 presents the results, and Section 7 concludes.

\section{Prior Evidence}

The analysis in this paper speaks most directly to the economics literature on employment protection. Most previous research in this area focuses on how employment protection can inhibit a firm from adjusting in response to economic shocks or changes in 
technology and examines outcomes such as worker mobility and employment levels (Bertola 1990; Lazear 1990; Hopenhayn and Rogerson 1993). ${ }^{6}$ However, firms may also want to dismiss workers because of poor performance, in which case one would be concerned with the impact of employment protections on worker effort and firm productivity.

Surprisingly few studies have examined the impact of employment protection on worker behavior. In the study most closely related to our analysis, Ichino and Riphahn (2004) use detailed personnel data from an Italian Bank to examine whether worker absenteeism changes after the three-month mark, when bank employees are granted tenure. Looking at changes in absenteeism within employers over time, the authors find that when men get tenure their absence rate more than triples. Interestingly, they find no comparable effect for women.

Martins (2009) examines the impact of legislation that restricted firings for cause in Portugal, using a difference-in-difference approach that exploits the fact that many provisions of the law did not apply to small firms. While he does not find any robust effects on job or worker flows, the author does find that small firms experienced sizeable increases in their performance (as measured by sales per worker) relative to large firms after the introduction of the legislation. The author finds no evidence of either capital deepening or observable changes in worker composition in small firms, leading him to conclude that the effect is driven by increases in worker effort and/or changes in management practices.

\footnotetext{
${ }^{6}$ While employment protection should unambiguously reduce job flows, in many models the theoretical impact of employment protection on employment levels is ambiguous, as higher firing costs reduce both firing and hiring (Bertola 1992). Recent research using worker- or firm-level data is mixed, although there is some evidence that commonly adopted employment protection may reduce job mobility and employment (for important recent papers in this literature, see Kugler 1999, Hunt 2000, Bauer et al. 2007, Friesen 2005, Kugler and Pica 2007, Autor et al. 2006, Marinescu 2009).
} 
Several other studies examine the effects on worker behavior less directly. For example, a related line of research examines the impact of wrongful discharge laws in the United States. ${ }^{7}$ Using the variation in dismissal costs generated by the adoption of wrongful-discharge protection by state courts, Autor et al. (2007) find that one of three main wrongful-discharge provisions, the good-faith exception, seems to decrease total factor productivity. However, the authors caution that this result is not particularly robust, in part because the good-faith exception does not seem to impact employment or wages. Indeed, the one provision that the authors find does impact employment, the implied-contract exception, does not seem to impact productivity. ${ }^{8}$

This paper also speaks to the growing literature on teacher incentives, a line of research that fits within the broader work on employee incentives within the personnel economics literature (see Pendergast 1999 for a review of the literature on employee incentives). Research on teacher incentives has focused on two types of policies that arguably provide enhanced incentives for teacher performance: merit pay or other compensation schemes that link pay to student performance, and school accountability policies that tie rewards or sanctions to student performance. Two recent reviews of pay-for-performance in education conclude that the existing evidence on merit pay is limited and shows mixed results (Springer and Podgursky 2008, Lavy 2008). There is some compelling evidence that well-structured teacher incentives

\footnotetext{
${ }^{7}$ In a series of more recent papers, Autor et al. (2004, 2006 and 2007) reconcile the conflicting findings from prior research and find evidence that one wrongful-discharge provision (i.e., the implied-contract exception) reduced employment rates, but that the two other major provisions (i.e., the public-policy and good-faith exceptions) had no robust employment or wage effects.

${ }^{8}$ Using similar variation as Autor et al. (2006), Bird and Knopf (2009) find that wrongful discharge protections increased labor expenses and reduced profitability in the commercial banking sector and Petrin and Sivadasan (2006) find that employment protection increased the gap between marginal revenue product and wages. Besley and Burgess (2004) find that Indian states that reformed laws in a pro-worker direction experienced lower output, employment, investment and productivity in the formal sector, as well as an increase in urban poverty.
} 
can substantially improve student performance, but this research comes from developing countries like Kenya and India and may not generalize well to schooling in developed countries. ${ }^{9}$

In the area of school accountability, some evidence suggests that policies that link consequential sanctions to student performance do improve student achievement, particularly in math (Jacob 2005, Hanushek and Raymond 2005). Similarly, Dee and Jacob (2011) find that the federal No Child Left Behind legislation increased math performance. Ahn (2011) uses data on teacher absences to examine teacher effort in the context of the North Carolina school accountability system, which rewards teachers for academic growth at the school-level. He finds that schools with a moderate likelihood of winning the bonus exert high levels, and that effort strongly predicts student achievement. On the other hand, there is evidence that such accountability policies often lead to unintended, negative consequences (Jacob 2005, Figlio and Winick 2005, Neal and Schanzenbach 2009). Furthermore, school accountability policies, including the federal No Child Left Behind Act, provide no direct incentives for teachers and thus do not provide a compelling test of the type of employment protection policies studied here.

Finally, a recent paper provides evidence that teachers respond to the implicit incentives generated by career concerns. Using data on public school teachers in North Carolina, Hansen (2009a) finds that teacher absences are positively correlated with both experience and tenure in a particular school, and absences increase dramatically in the year prior teacher retirement or departure. While this study sheds light on teacher incentives broadly, it does not speak directly to the potential impact of a change in teacher tenure policy.

\footnotetext{
${ }^{9}$ While pay-for-performance has been around for many years in public education, it has received increasing attention in recent years. This has led to a dramatic increase in the number of districts experimenting with some form of merit pay, and to more research on the impact of such policies. Several ongoing studies, including a random assignment evaluation in Nashville, TN, promise to shed more light on the prospects for merit pay in education.
} 


\section{Background}

\subsection{Teacher Dismissal Policy in the Chicago Public Schools}

As in many public school districts, teacher layoffs and dismissals in the Chicago Public Schools are highly regulated. In situations where teacher positions must be eliminated due to enrollment changes or a budget shortfall, the collective bargaining agreement outlines a procedure by which the least experienced teachers are let go first. This is typically known as a reduction-in-force (RIF).

In the past, it has been extremely difficult for principals to dismiss teachers outside the auspices of a RIF. Like most other districts, the collective bargaining agreement in Chicago provides considerable protection for tenured teachers that make it very time-consuming and difficult for principals to dismiss these teachers for cause. Unlike many smaller, suburban districts in Illinois, however, the collective bargaining agreement in Chicago also made it very difficult for principals to dismiss non-tenured teachers. ${ }^{10}$ Perhaps for this reason, formal principal evaluations in Chicago are remarkably generous. In 2007, for example, only 15 out of the 11,621 teachers who were evaluated in 2007 received a rating of unsatisfactory, and only 641 out of 11,621 (roughly 5.5 percent) received a rating of satisfactory. The remaining teachers were rated excellent or superior. ${ }^{11}$

\footnotetext{
${ }^{10}$ The contract in place from 1999-2003 specified that if a principal wanted to give a probationary or substitute teacher an unsatisfactory rating, the principal needed to notify the teacher in writing and send the notice to several different units within the district office. The principal then had to meet with the teacher at least 3 additional times, providing written feedback and suggestions following each meeting. A district official also had to meet with the teacher, again providing written feedback. If, after 40 days, the teacher's performance did not improve, the principal had to submit another form to the teacher, with copies distributed to various units within the district office. The Department of Personnel then called a conference that included the teacher, the principal and the district superintendent (or his designee). At the end of this conference, a recommendation was made to the superintendent regarding the action to be taken (CTU 1999).

${ }^{11}$ Statistics based on author's calculations using administrative data provided for this study.
} 
The adoption of a new collective bargaining agreement on July 1, 2004 made substantial changes to the tenure system in Chicago that, for the first time in the 2004-05 school year, provided principals with the ability to easily dismiss non-tenured teachers. So, in the analysis that follows, the academic years 2002-03 through 2003-04 constitute the "pre-policy" period and the academic years 2004-05 through 2007-08 constitute the "post-policy” period. The July 2004 contract created a new three-tiered classification system for Chicago teachers: (1) Temporarily Assigned Teachers (TATs) include individuals who are in a temporary placement (such as a long-term substitute who is filling in for a teacher on leave) and are not earning tenure; (2) Probationary Appointed Teachers (PATs) include individuals who have been regularly appointed to a position but have been teaching for fewer than five consecutive years (i.e., during this period, Chicago teachers received tenure after four years of service) and; (3) tenured teachers. Prior to the introduction of the non-renewal policy, there was a category of teachers who were fully credentialed, but not formally appointed to a position (i.e., not on the "tenure track"). These "unassigned" teachers composed roughly one-quarter of all probationary teachers in 200304. When the policy was implemented in 2004-05, all of these previously "unassigned" teachers were formally appointed (i.e., assigned). From this point forward, the contract specified that all fully certified teachers that were hired were to be assigned immediately. In other words, the district would not employ any "adjuncts" - only tenure track teachers. ${ }^{12}$

Non-renewal works in the following way. Each February, principals are able to log into a district computer system that has a list of all of the PATs in their school. The principal can then check one of two boxes: renew or non-renew. ${ }^{13}$ The administrative ease with which

\footnotetext{
${ }^{12}$ District officials describe this as one concession the union got in return for the enhanced authority given to principals.

${ }^{13}$ If the principal checks the "non-renewal" box, he or she must check indicate at least one of the following five specific reasons for the non-renewal (note, the wording of these listed reasons match exactly the listed reasons
} 
administrators can dismiss a probationary teacher - with a simple "click" of a button - is noteworthy. In essence, the collective bargaining agreement adopted in July 2004 dramatically reduced the costs of firing a probationary teacher in the district. This policy change made Chicago the only large, public school district in the country to provide principals with this type of flexibility over personnel decisions. ${ }^{14}$

While teachers are notified by formal letter of non-renewal sometime in late April or early May, discussions with district officials suggest that many principals tell teachers in March, as soon as they have made their decision. If a principal chooses to non-renew a teacher, the teacher is guaranteed health benefits through August $31^{\text {st }}$ of the current year, and is allowed to reapply to positions in other Chicago public schools. Moreover, the teacher is eligible for unemployment benefits as non-renewal is viewed as a layoff rather than a dismissal for cause. ${ }^{15}$ However, non-renewed teachers are not guaranteed another job in the CPS. ${ }^{16}$ Although principals are required to provide district officials with at least one reason for the non-renewal decision, they are not required to justify or explain their decision and they do not need to provide teachers with this reason. ${ }^{17}$

principals chose from): deficiencies with instruction (e.g., planning, methods, subject matter knowledge), deficiencies with environment (e.g., classroom management, teacher-pupil relationships), deficiencies with professional and personal responsibilities (e.g., attendance, tardiness, professional judgment), deficiencies with communication (e.g., parent conference skills, relations with staff), or deficiencies with attitude (e.g., lack of cooperation, lack of respect for others).

${ }^{14}$ Principals are not required to make any decision for a particular teacher. If a principal either chooses to renew a PAT or takes no action, then the teacher is still eligible to be laid off through the standard RIF process.

${ }^{15}$ PATs who are rehired by November $1^{\text {st }}$ will not experience a break in service for tenure purposes.

${ }^{16}$ PATs who are displaced through the standard RIF process are also guaranteed health benefits through August $31^{\text {st }}$ and eligible for unemployment insurance. However, they are also guaranteed a position as a cadre teacher, which means that they are guaranteed work as a substitute every day and receive a higher rate of pay and better benefits than a day-to-day substitute. In contrast, non-renewed teachers have to apply to be a cadre teacher, and are accepted on a case-by-case basis after displaced PATs. Tenured teachers who are displaced through the RIF process receive even more benefits. Personal communication with Nancy Slavin, Director of Teacher Recruitment, Chicago Public Schools, June 22, 2007.

${ }^{17}$ If a principal chooses to non-renew a PAT in his or her fourth year (that is, immediately prior to tenure), the principal is required to inform the teacher which reason(s) were listed, but is not required to further justify or explain the decision. 


\subsection{Conceptual Framework}

A simple economic model suggests that the reduction in firing costs could influence worker effort and productivity ${ }^{18}$ in one of two primary ways: by changing the behavior of existing workers and/or by changing the composition of workers in the firm. For many workers, lower firing costs will induce greater effort by creating a stronger link between job performance and continued employment. Lower firing costs could also change the composition of workers in the firm. If the effort required to avoid dismissal is sufficiently costly for a particular employee, for example, the policy might induce her to quit. Perhaps more importantly, the reduction in firing costs will likely lead the firm to dismiss a larger fraction of workers.

The impact of such compositional changes on worker productivity depends on a variety of factors including the principal preferences (e.g., the type of teacher the principal chooses to dismiss and the type hired as the replacement) and the elasticity of supply for teacher quality. If principals dismiss probationary teachers with below average productivity, supply is relatively inelastic, and principals do not change their hiring behavior, then one would expect the average productivity in the school to rise over time. ${ }^{192021}$

\footnotetext{
${ }^{18}$ I use the term effort and productivity interchangeably in this discussion.

${ }^{19}$ The policy might also impact worker productivity by altering hiring practices in other ways. The ability to easily dismiss probationary teachers essentially decreases the cost of hiring a new teacher if one considers the expected difficulty of dismissing an ineffective teacher as part of the cost. All else equal, this will increase a principal's likelihood of hiring a "higher-risk" teacher - that is, a teacher about whom the principal has less information with regard to job performance. For example, the introduction of the renewal policy might make principals more inclined to hire teachers with alternative certification, or individuals entering teaching as a second career. Assuming that principals are risk-averse in their hiring practices, this might increase the overall productivity of the teacher workforce. Moreover, to the extent that principals differ in their ability to identify effective teachers (pre- or posthire), this policy might exacerbate across-school differences in teacher quality.

${ }^{20}$ There are several other potential channels through which a reduction in firing costs among a subset of teacher might influence teacher productivity. Autor (2003) notes that employment protection policies may reduce the incentive of employees to invest in firm-specific skills, which could lower productivity. Martins (2009) discusses how a reduction in firing costs may lead a firm to change its management practices.

${ }^{21}$ Finally, the policy could impact productivity by influencing teacher supply more generally. The introduction of the renewal policy increased the risk associated with a new teaching position in the CPS. In the absence of any
} 


\subsection{Some Basic Facts about Teacher Dismissals}

Table 1 provides summary statistics on the prevalence of teacher dismissal under this new policy. Several interesting facts stand out. First, roughly 1,000 teachers $(10-13$ percent of all probationary teachers in the system) were dismissed each in the early years of the policy. Considering that essentially zero teachers were dismissed for cause prior to the introduction of this policy, this represents an enormous policy change.

However, the number of teachers who were non-renewed in any given year likely overstates the impact of the policy because a number of young teachers would likely have left the CPS in the absence of the policy, either voluntarily or due to subtle "encouragement" on the part of the principals. If the dismissal policy merely formalized previously informal dismissals, then one would not necessarily expect to find a substantial change in separations. Even in this case, however, the policy may have influenced teacher productivity if it changed the expectation or transparency of the dismissal process.

To shed light on these issues, Table 2 presents statistics on teacher mobility before and after the implementation of the non-renewal policy. Among first-year teachers, attrition rates are substantially larger under the new policy. For example, nearly 19 percent of first-year teachers in 2005 left the district by the following year compared with less than 8 percent in the prior year. This type of dramatic increase is not apparent among more experienced teachers (defined as

increase in financial compensation, the policy will make teaching positions in the CPS less attractive for risk-averse individuals, which will tend to shift the supply curve inward. In practice, however, this does not seem to have happened in Chicago. Based on my conversations with district officials and a review of teacher application files over this period, it appears that neither the number of applicants per available position nor the observable characteristics of applicants changed noticeably after the introduction of the policy. Moreover, the number of voluntary exits among new teachers has not increased in recent years, although this statistic may be misleading if, prior to the policy, a larger fraction of the officially voluntary exits were actually "encouraged" on the part of school administrators. Unfortunately, there is no way to distinguish truly voluntary versus involuntary exits prior to the introduction of the policy. 
those with 5-15 years of experience). ${ }^{22}$ These results suggest that the dismissal policy had at least a modest impact on teacher separations, although the impact is not as large as the overall nonrenewal numbers would suggest. ${ }^{23}$

Jacob (2011) studies principal decision-making under the new policy, finding evidence that principals systematically consider various proxies for teacher productivity in determining which teachers to dismiss. For example, all else equal, principals are more likely to dismiss teachers with lower value-added and more absences, and less likely to dismiss teachers who attended more selective colleges. Interestingly, while thousands of teachers were dismissed under this policy, roughly 40 percent of schools (including many low-performing schools) did not dismiss any teachers. Indeed, Jacob (2011) finds that there was considerable variation across principals in use of the policy, even after one controls for a rich set of observable teacher, school and principal characteristics.

\section{Empirical Strategy}

To estimate the impact of the policy on teacher effort, I utilize a simple difference-indifference (DD) estimator that compares changes in absence rates between teachers who were subject to the policy and those who were not. The control group in the baseline analysis consists

\footnotetext{
${ }^{22}$ There is an anomalous drop in attrition rates among first year teachers in 2003. Only 3.4 percent of teachers left the district from this cohort, compared with nearly 8 percent in 2002 and 2004. I have not been able to determine the cause of this decline and then recovery. There is also a noticeable jump in the fraction of young teachers who switch schools from the 2004 to the 2005 school year. Both facts might be due to the relatively large number of school closings and openings in 2003 and 2004. District officials seem to believe these patterns are simply random fluctuation, although I have no way of verifying this.

${ }^{23}$ An alternate strategy for estimating the fraction of dismissed teachers who would not have left voluntarily is to compare the separation rates of renewed vs. non-renewed teachers under the new policy. Among those first-year teachers in 2004-05 who were renewed, only 89 percent were teaching in the CPS in the following year (and 11 percent left voluntarily). In comparison, 56 percent of first-year teachers who were not renewed in 2004-05 ended up teaching in the CPS in the following year. Assuming that 11 percent of the non-renewed teachers would have left voluntarily as was the case with the renewed teachers, I can calculate that 75 percent $[(.44-.11) /(.44)=.75]$ of the separations among non-renewed teachers were involuntary; or rather, would not have occurred in the absence of the policy.
} 
of all tenured teachers, although I later show that our results are robust to other plausible control groups (e.g., only young, tenured teachers). The treatment group includes all untenured teachers, although I later show that the results are robust to limiting the treatment group to either probationary or temporary teachers. ${ }^{24}$

For the baseline specification, I estimate the following regression via OLS:

$$
\begin{aligned}
A_{\text {iset }}= & \beta_{0}+\beta_{1} \text { untenured }+\beta_{2} \text { post }+\beta_{3} \text { untenured }^{*} \text { post }+ \\
& \operatorname{Exp}_{e}+X_{i}+Z_{\text {st }}+\delta_{t}+\lambda_{s}+\varepsilon_{\text {iset }}
\end{aligned}
$$

where $A_{\text {iset }}$ is a measure of absences for teacher $i$ in school $s$ with experience $e$ (e.g., first-year teacher, second-year teacher, etc.) in year $t$. As described below, the data includes information on teachers from 2003 through 2008. The variable post is an indicator that takes on the value of one in years following the introduction of the policy (i.e., 2005-2008). Tenured teachers are the omitted category. Note that these job status variables are time varying indicators so, for example, an individual teacher may appear as untenured in one year and tenured in subsequent years. ${ }^{25}$

In all models, I also include time (i.e., academic year) fixed effects denoted by $\delta_{t}$, school fixed effects denoted by $\lambda_{s}$, and a full set of teacher experience indicators denoted by $\operatorname{Exp} .^{26}$ In

\footnotetext{
${ }^{24}$ Temporary teachers include individuals who are not fully credentialed and were (in theory) easier to dismiss even before the introduction of the new policy. Under the new policy, temporary teachers must be appointed to positions as they become available, at which point they become probationary teachers and start earning tenure. The relevant teacher contract provisions state: "A TAT who is assigned to a vacant position [at the time the new contract was adopted] shall be appointed as a probationary teacher." [CPS 23A-4.1.] "When a TAT is assigned to a position for a teacher on leave and that position becomes vacant, then TAT shall be appointed as a probationary teacher to such position within ten (10) days of the date on which the position became a vacancy.” [CPS 23A-4.2.]

${ }_{25}$ One might be concerned about including probationary teachers who became tenured under the new policy. By definition, these teachers were not dismissed, and thus presumably have higher productivity than the average teacher from the same cohort. By including the post-tenure observations for these "survivors" in the analysis, one may be inflating the productivity of the control group in later years. I later show that, in practice, the exclusion of these teacher-year observations does not substantially change our estimates. Hence, for simplicity, I include them in the baseline specification.

${ }^{26}$ In practice, teacher experience is incorporated slightly differently. As noted above, a clear and non-linear relationship between experience and absences existed prior to the introduction of the policy. I would like to include a full set of teacher experience effects in order to control for both potential secular trends in the experience
} 
some specifications, I also include teacher characteristics $(X)$ and school-year characteristics $(Z)$

as well. The coefficient on the interaction between Untenured and post, $\beta_{3}$, measures the net effect of the policy.

This model makes several identifying assumptions. First, it assumes that the policy was unanticipated. If teachers were aware of the impending changes during 2003-04, for example, then they may have altered their behavior in ways that would bias the estimate (e.g., young teachers may have worked harder in an effort to avoid dismissal in the following years, which would lead one to underestimate any productivity improvements). My conversations with district administrators responsible for negotiating the new collective bargaining agreement in 2004 suggest that neither teachers nor administrators were aware of this policy until close to the time of ratification in July 2004.

Second, the analysis assumes that there are no productivity spillovers between eligible and ineligible teachers. If, for example, greater effort on the part of probationary teachers induced greater effort on the part of tenured teachers in a school, the DD estimate would tend to understate any positive impact of the policy. ${ }^{27}$ While it is possible that such spillovers exist, I assume that these effects are small relative to the direct impact of the policy. Finally, the analysis assumes that, conditional on the covariates included in the model, there are no unobservable

distribution of Chicago teachers over this period, as well as the fact that the policy will explicitly shift the experience distribution of untenured teachers. Because the new policy mandates all new teachers be immediately placed on the tenure track, untenured teachers after the policy will tend to be less experienced than untenured teachers before the policy change. Note, however, that the policy itself is predicted to change this experience gradient since the designation untenured is itself a function of experience. I do not want to "control" for this type of change in the experience gradient. To do so, I measure the relationship between teacher experience and absences that existed prior to the introduction of the new policy, and use this to adjust the predicted absences of all teachers in the sample. Specifically, using only pre-policy data (i.e., years 2003 and 2004), I regress teacher absences on a full set of experience effects. I then use the resulting coefficients to calculate an absence residual for all teachers - both pre- and post-policy - and use this residual as the primary outcome measure in all of the models. I do the same thing for all of the alternative absence measures (e.g., the binary indicator for frequent absences, the measure of absences from September to March each year, etc.).

${ }^{27}$ For example, Jackson and Bruegmann (2009) find some evidence of teacher peer effects. 
time-varying factors that might confound the analysis. In the section that follows, I present a variety of sensitivity analyses to support this assumption. As noted above, the policy can operate through both incentive and compositional effects. To distinguish between these two mechanisms, in some models I include teacher fixed effects. ${ }^{28}$ If the treatment effect is homogenous, as assumed in equation (1.1), this approach will allow one to cleanly distinguish between these two mechanisms. If, however, the impact of the policy varies (e.g., by the calendar year, the teacher's experience level, the length of time the principal has known the teacher or other factors), then it will not be possible to cleanly disentangle incentive vs. compositional impacts. For example, teacher fixed effects models will not allow me to capture the incentive effect for first-year teachers because, by construction, one can only have been in his or her first year under one of the two regimes.

In order to examine the heterogeneity of effects across time-invariant teacher and school characteristics, I simply estimate equation (1.1) for different subgroups. To examine heterogeneity along other dimensions, I expand the baseline model and estimate:

$$
\begin{aligned}
A_{\text {iset }}= & \beta_{0}+\beta_{1} \text { untenured }+\beta_{2} \text { untenured } * \text { post }+\beta_{3} \text { untenured } * \text { riskyr } 2+ \\
& \beta_{4} \text { untenured } * \text { riskyr } 3+\beta_{5} \text { untenured } * \text { yr } 2006+\beta_{6} \text { untenured } * \text { yr } 2007+ \\
& \beta_{7} \text { untenured } * \text { yr } 2008+\beta_{8} \text { NewToSchool }+\beta_{9} \text { Survived }+\beta_{10} \text { FiredBefore }+ \\
& \text { Exp }_{e}+X_{i}+Z_{\text {st }}+\delta_{t}+\lambda_{s}+\varepsilon_{\text {iset }}
\end{aligned}
$$

The interactions between untenured and the risk year indicators (i.e., riskyr2 and riskyr3) allow the impact of the policy to vary based on whether a teacher has "survived" dismissal in previous years. Risk year is defined as the number of years an untenured teacher has worked in a particular school under the new regime. Prior to the policy, all teachers have a value of zero. In 2005, all untenured teachers are coded as risk year equals one. In 2006, newly hired teachers

\footnotetext{
${ }^{28}$ In addition to focusing exclusively on the incentive effects, this approach allows one to rule out potential confounders related to composition changes such as an unrelated influx of high quality individuals from other occupations spurred by a weak local economy.
} 
will have a value of one and teachers who "survived" dismissal in 2005 and remained at the same school are coded as having risk year equal to two. Untenured teachers who switched schools within the district between 2005 and 2006 are coded as risk year one again in 2006 because of prior literature suggesting that firm-specific tenure (as opposed to simply experience) is critical aspect of job security. A variety of models of employer learning imply that the incentives might diminish with time spent at a particular school under the new regime (e.g., Jovanovic 1979). ${ }^{29}$

The interactions between untenured and academic years 2006 through 2008 allow the effect of the policy to vary with the years following implementation. If, for example, principals and teachers learn slowly about the policy, one might expect the policy effects to increase in later years.

The inclusion of an indicator for whether the teacher was dismissed in a prior year is meant to capture the change in effort associated with the actual realization of being dismissed. In the absence of teacher fixed effects, this coefficient will also capture any unobserved factors associated with the fact that the teacher was dismissed (perhaps a negative unobservable), but then rehired at a different school (perhaps a positive unobservable). The inclusion of the "new to school” indicator (which applies to all teachers, tenured or not) controls for any change in effort that is associated with switching schools, independent of dismissal.

In estimating the standard errors on the key policy parameter, $\beta_{3}$ in equation 1.1 , it is important to take account for the heteroskedasticity and non-independence of the errors in the data (Bertrand et al. 2004). In the baseline specification, I present cluster-robust standard errors using school as the cluster variable. This will accommodate non-independence of errors within

\footnotetext{
${ }^{29}$ In models without teacher fixed effects, risk year will also incorporate some compositional effects since, by definition, teachers with higher values will have "survived" dismissal in the past, and might therefore be positively selected.
} 
schools, in a given year and over time, and will (to a large extent) accommodate nonindependence within teachers since the majority of teachers in the sample remain in the same school over the relatively short period of this study. However, the policy variation I examine in this analysis occurs at the level of tenure status x year. In this sense, there are effectively 12 groups ( 6 years $x$ tenured vs. untenured) driving the policy impact. To the extent that there is substantial intraclass correlation within these groups, the precision of the baseline estimates may be considerably overstated. Given there are only 12 groups, cluster-robust standard errors at the level of year $\mathrm{x}$ tenure status may not be consistent (Cameron et al. 2008).

Instead, I use the two-step GLS procedure recommended in Donald and Lang (2007). In the first step, I estimate equation (1.1) replacing the tenure status and year variables with 12 binary indicators for year $\mathrm{x}$ tenure status. In the second step, I estimate a regression with 12 observations in which the coefficients on the 12 group indicators from step one are the dependent variables and the independent variables include separate year indicators, an indicator for untenured, and the interaction post $\mathrm{x}$ untenured. I use the covariance matrix of the 12 group fixed effects from step one to weight the regression in step two. Following Donald and Lang (2007), I use a t-distribution with (n-k) degrees of freedom to conduct inference. In my case, there are only 4 degrees of freedom (i.e., 12 observations -7 covariates -1 constant term).

As I show below, the two-step GLS estimation produces standard errors virtually identical to those shown in the baseline specification, indicating that there is very little intraclass correlation in teacher absences. Using the t-distribution with the 4 degrees of freedom, the baseline absence estimate is significant with a p-value of .0005. 


\section{Data}

The data for this study comes from several sources. Teacher personnel files provide information on teacher background, current assignment and renewal decisions. I supplement this teacher-level data with information on school demographics, principal characteristics from personnel files, and student test score information.

To determine a teacher’s job status, I rely on administrative teacher assignment data provided by the CPS. ${ }^{30}$ Teacher absence data from payroll records serve as our primary measure of teacher effort. This measure is appealing for several reasons. First, absences are measured extremely well in the payroll data and they are easily interpretable. Second, teacher absences impose substantial financial costs on the district, which has to pay for substitute teachers, as well as non-pecuniary costs on school administrators and other teachers who must juggle schedules to accommodate an absent colleague. Third, several recent studies have documented that teacher absences have a strong, negative association with student achievement, providing evidence that this association is causal (Clotfelter et al. 2007, Miller et al. 2007). ${ }^{31}$ Indeed, in other work using Chicago data from a similar time period, I show that a teacher's absences are negatively associated with principal evaluations of the teacher and with a teacher's value-added contribution to student achievement (Jacob and Walsh 2011). Finally, there is considerable evidence that

\footnotetext{
${ }^{30}$ Starting in 2004-05, district files clearly identify whether a teacher is a temporary, probationary or tenured teacher. In earlier years, temporary teachers are clearly identified but the district did not utilize a comparable classification system for other teachers, so I determine job status using information on a teacher's tenure date, along with an audit conducted by the district in the Summer of 2004 in order to verify each teacher's status prior to the implementation of the new regime.

${ }^{31}$ Using North Carolina data, Clotfelter et al. (2007) employ teacher fixed effects and find that each 10 days of teacher absences decrease student achievement by 2.6 percent of a standard deviation. Miller et al. (2007, forthcoming) focus on one disadvantaged urban district and also use teacher fixed effects. They find that each 10 days of teacher absences reduce students' mathematics achievement by 3.3 percent of a standard deviation. In the context of a developing economy, Duflo and Hanna (2006) provide experimental evidence that teacher absences reduce student performance.
} 
absences are at least partly discretionary. Research suggests that teacher absences are more frequent on Mondays and Fridays (ERS 1980), higher among temporary teachers and correlated with more general shirking in the workplace (Bradley et al. 2007) and negatively associated with buy-back provisions that allow teachers to receive payment for unused absences (Ehrenberg et al. 1991). Hansen (2009a) finds that teacher absences in NC correspond to experience, tenure in a school, the presence of a new principal and proximity to retirement in ways that would suggest absences are a good proxy for discretionary effort.

Teachers in Chicago are allotted 10-12 paid sick or personal days per year. Teachers can accumulate unused sick days across years, up to a maximum of 315 days. These days can be cashed in upon leaving the district at a rate of $100 \%$ for those teachers retiring with at least 40 years of experience and at a 90\% rate for teachers with 20-40 years of experience. In addition, teachers get 3 personal days per year, which can be used for emergencies, religious holidays or personal business. There are some restrictions regarding the use of personal days (e.g., teachers cannot use all three days in succession and they cannot be used in the first or last week of school, or on a day before or after a holiday), although unused personal days get banked as sick days. ${ }^{32}$

The primary outcome measure is simply the total number of days that each teacher was absent during the academic year, which generally runs from the beginning of September through mid-June, excluding “excused absences” for professional development or other sanctioned activities. $^{33}$ I also present results using indicators for frequent and/or inappropriate absences as

\footnotetext{
${ }^{32}$ Information on teacher absence policy comes from a review of the recent CPS teacher collective bargaining agreements. Teachers with 13+ years of experience are entitled to 11 paid sick/personal days per year and (as of 2008) teachers with 18+ years of experience are entitled to 12 paid days. Starting in 2009, teachers were allowed to accumulate up to 320 days of sick leave across years. Teachers who retire at age 65 or older they would get to cash in $85 \%$ of their sick days. Teachers who retire before 65 years of age with less than 20 years of experience cannot cash in any of their sick days. For leaves due to illness over 10 days, teachers must apply for a personal illness leave.

${ }^{33}$ Unfortunately, I do not have additional detail such as whether the teacher notified the principal ahead of time, or simply did not show up in school.
} 
the outcome (e.g., indicator for 15+ absences during the year, number of absences on Fridays, or fraction of total absences on Mondays or Fridays, etc.).

Table 3 presents summary statistics on the final sample of 35,859 teachers over 6 years (138,731 teacher-year observations). Looking down column 1, one sees that roughly 77 percent of teachers are women, 48 percent are white, 34 percent are Black and 14 percent are Hispanic. The average age is 44 years, but 25 percent of teachers are less than 33 years old. Over 50 percent of teachers received a BA in education, and 16 percent of teachers in the sample had failed at least one certification exam in the past, and 26 percent had never passed a certification exam. ${ }^{34}$ Columns 2-5 present statistics separately for tenured and untenured teachers in pre- and post-reform years. Most interestingly, one sees that the number of absences drop by over 1 day per year (nearly 14 percent) for untenured teachers, but remain roughly the same for tenured teachers. These descriptive statistics thus provide the first indication that the new dismissal policy may have impacted teacher effort.

\section{Results}

I begin by showing the unadjusted trends of teacher absences by job status. Figure 1 shows the trends in absences from 2003 through 2008 separately for tenured and untenured teachers. Consistent with the pattern of higher absences among younger teachers, in 2003 the untenured group had roughly .25 more absences than the tenured group. Absences rose sharply for all teachers in 2004, although the increase among untenured teachers was noticeably larger than that among tenured teachers (1.5 absences versus 1 absence). District officials were not able to pinpoint a specific reason for the large increase in absences in 2004, although some did

\footnotetext{
${ }^{34}$ The group that has never passed a certification exam mainly includes older teachers who were grandfathered into the existing certification regime.
} 
note that it was the last year of the collective bargaining agreement and teachers may have been worried about changes in the new contract that could have impacted their banked sick and/or personal days. $^{35}$

Because this significant pre-policy jump might have important implications for the analysis, I confirm that all of my results are robust to excluding the 2004 school year entirely from the analysis (see below). Ideally, one would observe several years of teacher absences prior to the introduction of the new policy to characterize a pre-policy trend. Unfortunately, teacher absences are not available prior to the 2002-03 school year.

In 2005, absences for untenured teachers drop sharply (though it remains above the 2003 level) while absences among tenured teachers increase by .25 absences. Absences among untenured teachers continue to drop after 2005, falling from 9.3 in 2005 to 7.1 in 2008. Absences among tenured teachers also fall over this period, though less sharply than those of untenured teachers.

Trends in the fraction of "high-absence teachers" (i.e., teachers who are absent at least 15 times during a year), shown in Figure 1b, tell a similar story. If anything, the pattern of greater relative decline among untenured teachers after 2005 is even more noticeable in this figure.

Figures 2 and 3 present the analogous trends for elementary and high school teachers respectively. Interestingly, the unexpectedly large jump in absences among untenured teachers in 2004 appears limited to elementary schools. At the high school level, absences among both tenured and untenured teachers rose by roughly one day. More generally though, the pattern of larger relative declines among untenured teachers post policy is evident in both elementary and secondary teachers.

\footnotetext{
35 The increase from 2003 to 2004 is evident at all points in the absence distribution for both tenured and untenured teachers and is not driven by larger absences during a particular part of the school year (results available upon request).
} 
Table 4 presents baseline results from equation (1.1), which includes school, calendar year and experience year fixed effects. The results shown in column 1 imply that the dismissal policy reduced absences among untenured teachers by roughly one day, which corresponds to a reduction of roughly 11 percent of the pre-reform mean. ${ }^{36}$ In columns 2 and 3 , we see that using 2003 as the sole pre-policy observation yields a point estimate of -.748 days (8.7 percent reduction) while using 2004 as the sole pre-policy year yields a point estimate of -1.36 days (a 15.5 percent reduction).

The results shown in columns 5-7 suggest that the policy had an even larger impact on the incidence of more serious shirking, defined as being absent at least 15 days in the year, which corresponds to the $75^{\text {th }}$ percentile of the absence distribution. Using both 2003 and 2004, I find that the dismissal policy reduced the incidence of frequent absenteeism by 3.8 percentage points (30 percent). Unlike with the measure of days absent, the choice of pre-policy year does not materially affect the point estimates for frequent absences. Limiting the pre-policy sample to 2003 and 2004 respectively, I find that the policy reduced the incidence of frequent absenteeism by 3.8pp (30 percent) and 3.8pp (30 percent).$^{37}$

As noted above, this analysis assumes that there were no other explicit policies or other unobserved factors that would have affected tenured and untenured teachers differentially starting in 2005. In the context of the Chicago policy, one might be particularly concerned about factors that were changing either the composition or incentives of new/younger teachers in Chicago. ${ }^{38}$ A particular feature of the policy implementation provides a compelling test of this

\footnotetext{
${ }^{36}$ This is equivalent to an effect size of roughly the same size.

${ }^{37}$ Results are comparable using $10+$ and $20+$ absences.

${ }^{38}$ Based on a review of CPS policies during this time and informal conversations with district administrators, it does not appear that there were any other programs that one would have expected to influence outcomes such as teacher absenteeism differentially by job status (though there were clearly a number of policies aimed at reforming lowperforming schools, particularly at the secondary level).
} 
assumption. As described in the data section, before the introduction of the non-renewal policy, there was a category of teachers who were fully credentialed, but not formally appointed to a position (i.e., not on the "tenure track"). When the policy was implemented in 2004-05, all of these teachers were formally appointed and became first-year probationary teachers regardless of the number of years they had been working in the CPS. This effectively breaks the link between teacher experience and probationary status, allowing one to assess whether the purported policy effects are driven simply by changes among novice teachers. ${ }^{39}$

Figures $4 \mathrm{a}$ and $4 \mathrm{~b}$ show the trends in absences separately for teachers less than five years of experience (tenure was earned after four years of service during this period) and teachers with five or more years of service (using the same samples as in Figures 1a and 1b). If one thought that unobserved prior trends or concurrent policies most relevant for younger teachers were driving the apparent policy impact, then one would expect the trends in Figure 4 to resemble those in Figure 1. However, the new figures show a very different picture. Comparing the experienced versus inexperienced teachers, I see that the novice group has substantially fewer absences than more experienced teachers in all years but the trends among the groups are nearly identical. This suggests that the results above are not simply an artifact of some other unobserved phenomenon that disproportionately influenced novice teachers in Chicago over this period.

Columns 4 and 8 in Table 4 shows estimates that mirror Figures 4a and b - namely, our baseline specification but where the treatment group is defined as teachers with less than five years of experience. Consistent with Figure 4, there is no treatment effect in this specification.

\footnotetext{
${ }^{39}$ Even in the absence of this feature, there would have been some variation between teacher experience and job status because the experience variables in the CPS files correspond with when the teacher began working in the district in any capacity. A non-trivial fraction of teachers start in temporary or non-teaching positions, and then transition into standard teacher roles. In addition, some teachers that transfer from other districts can start in a higher job status.
} 
Figures 5 and 6 present comparable trends separately for elementary and high schools, revealing a similar pattern across the grade levels.

\subsection{Sensitivity analyses}

Table 5 shows that the main results described above are robust to a variety of alternative specifications. Rows 2-4 show the results are roughly comparable regardless of whether one measures absences using sick days, personal days or other absences. Row 5 shows that the results fall but are still significant if one excludes observations with more than 40 absences, under the assumption that these are cases of non-discretionary leaves for illness or other reasons.

Rows 6-7 show results separately for the periods September-March and April-June.

Because the non-renewal decision is made in late March, one would expect the majority of behavioral impacts to appear prior to this point. Consistent with this hypothesis, the impact of the new policy on absences is much greater prior to March (a reduction of absences by roughly 15 percent) than after March (a decline of only 4 percent). Row 8 shows that the results are robust to limiting the control group to include only young (i.e., teachers with 5-10 years of experience) tenured teachers.

Rows 9-11 show that the results are not particularly sensitive to the inclusion of school fixed effects, school-year characteristics or teacher demographics. Row 12 shows the two-step GLS procedure suggested by Donald and Lang (2007) and described above. The standard errors in this model are virtually identical to the baseline estimates. As noted above, the p-value of this estimate is .0005 using the t-distribution with the 4 degrees of freedom. Finally, rows 13-14 show that negative binomial and Poisson models produce comparable results - namely, the policy led to a roughly 10 percent reduction in teacher absences. Results from the same set of 
sensitivity analyses, separately for elementary and secondary schools, and for 15+ absences, shown in the on-line appendix, confirm these results.

\subsection{Treatment Effect Mechanisms and Heterogeneity}

Table 6 examines the extent to which the net policy impact consists of compositional versus incentive effects. Each cell corresponds to a separate regression (based on equation 1.1), where the estimate shown is the coefficient (s.e.) on the post $\mathrm{x}$ untenured indicator. The specification in row 1-column 1 reproduces the baseline estimate from column 1 of Table 4 . Column 2 estimates an identical model, but includes teacher fixed effects in lieu of school fixed effects. By relying exclusively on within teacher variation over time, this specification tells whether the policy has led individual teachers to reduce their absences. If not, then we can assume that the effect is being driven by changes in the teaching force. Such changes may come about in one of three ways: (1) teachers with the greatest propensity for being absent left the district to avoid the possibility of being dismissed; (2) such high absence teachers left because they were dismissed; or (3) teachers hired under the new regime had a lower propensity for being absent.

The results are striking. The inclusion of teacher fixed effects completely eliminates the entire policy effect, suggesting changes in the composition of the teaching force can fully explain the reduction in absences among untenured teachers after 2005. ${ }^{40}$

Given the multiple channels through which such compositional effects might operate, it is useful to explore the source of the effect. In order to eliminate any compositional effects that might arise through new hiring, row 2 shows results from a sample including only those teachers (tenured as well as untenured) who appeared in the sample prior to 2005. The results are

\footnotetext{
${ }^{40}$ Models that exclude 2004 yield comparable patterns of results.
} 
virtually identical, suggesting that the compositional changes were due to teachers leaving the district. In row 3, we further limit the sample to exclude all observations for any teacher who was dismissed under the new policy and subsequently left the district. Again, the pattern of results - particularly in the teacher fixed effects specification - is essentially unchanged. This suggests that the compositional effects were driven largely by the departure of untenured teachers who had been working in the district prior to 2005.

In order to further explore the source of the effect, it is useful to examine how the effect may have differed across different types of untenured teachers. As described in Section 3.1, it is useful to consider 4 different types of untenured teachers: (1) individuals who temporarily assigned to a position and may not have been fully certified (e.g., "full-time basis" substitute teachers); (2) individuals who were fully certified and appointed to the tenure track at the time of hire; (3) individuals who were fully certified and appointed the tenure track but only after working in the district for several years; and (4) individuals who were fully certified but not appointed the tenure track as of Summer 2004 when the new policy was introduced (note that this group was automatically placed on the tenure track starting in Fall 2004). Although a teacher's status is a time varying characteristic, teachers were categorized into groups based on their status in the first year they appear in the data. Hence, the control group includes all teachers who first appeared in the data as tenured teachers. To simplify the presentation, I show the results only for the sample in row 2, although the results are quite comparable if uses the row 3 sample.

Focusing on columns 3-4, we see that the results for the set of temporarily-assigned (i.e., full-time substitute) teachers mirror those of the full sample - namely, large, negative coefficients in the school fixed effect model but no significant effect in the teacher fixed effect 
model. This suggests that the policy caused the individuals in this group of untenured teachers with the highest propensity to be absent to leave the system, and not that the policy led individuals in this group to be absent less often.

Columns 5-6 indicate that the policy had little impact, on average, for the set of untenured teachers who were placed on the tenure track at the time of initial hire. While this is what many would consider typical, given that fewer than half of newly hired regular classroom teachers in Chicago in 2003 and 2004 were in this category, this is likely a positively selected group. For this group, we find no significant policy effects, with either school or teacher fixed effects.

Columns 7-8 show a similar pattern for the set of teachers who were appointed to the tenure track, but only after working in the district for several years. ${ }^{41}$ Most likely this group is less positively selected than the prior group, but more positively selected than the Group 4 teachers. For this group, we see no policy effect with school fixed effects, and a positive effect with teacher fixed effects, suggesting that individual teachers in this group may have increased their absences slightly in response to the policy.

Columns 9-10 reveal that the largest compositional effect was coming from what one might consider the most negatively selected set of untenured teachers - i.e., individuals who were fully certified and in many cases had been working as regular classroom teachers in the district for years, but who had not been appointed to the tenure track at the time the new policy was introduced. The school fixed effect estimates indicate a reduction of two full absences while the teacher fixed effect estimates suggest, if any, a small increase in the number of absences.

\footnotetext{
${ }^{41}$ It is possible that these individuals started in a non-teaching position in the district, and only recently started as a teacher. Alternatively, these individuals may have started as unassigned teachers, and were only recently assigned.
} 
The results above indicate that the compositional effects seem in columns 1-2 were driven largely by the exit of "low-productivity" teachers who had been working as temporarilyassigned teachers or untenured teachers who had not been appointed to the tenure track. It is worth reiterating that, unlike some other analyses, the fact that the impact of the policy is driven by compositional changes is not evidence of a zero causal effect. In the case of the dismissal policy, composition was one of the legitimate and intended channels through which the district hoped to increase teacher effort.

While the results shown in Table 6 help to disentangle compositional from incentive effects, they might obscure potentially important heterogeneity in the incentive effects. Table 7 presents teacher fixed effects estimates from equation (1.2) that allows the effect of the policy to vary by the number of years following implementation, whether the teacher and/or principal was new to the school and the number of years a teacher has prior to tenure.

Focusing on the full sample results in Column 1, we see that the policy had no significant effect on absences in 2005, at which point all untenured teachers were - by construction - in their first year "at risk" under the policy. Because various models of employer learning imply that the incentives might diminish with time spent at a particular school (e.g., Jovanovic 1979), we included interactions that allow the policy effect to vary with a teacher's risk year. Interestingly, we find no significant effects. However, we do see some significant interactions with calendar year such that the policy seems to have reduced individual teacher absences in the later years. In 2007 and 2008, for example, the policy is associated with a reduction of roughly one-half of an absence per year (a decline of roughly 5 percent).

Finally, it is reassuring to see a large, negative coefficient on the prior dismissal variable, indicating that having been dismissed through the policy is associated with a large increase in 
effort. In interpreting this coefficient, it is important to recall that teachers who were dismissed are clearly not a random sample of untenured teachers, and those who were rehired by a different school the subsequent year were clearly a non-random set of all dismissed teachers. The comparable coefficient estimates from a model with school instead of teacher fixed effects yield point estimates that are somewhat smaller (in absolute value), though still highly significant and economically important. While the teacher fixed effect estimates control for composition, they are more susceptible to bias due to regression to the mean or some other form of time-varying omitted variable.

Columns 2 and 3 show results for Groups 1 and 2 from the previous table, as these are groups that existed under both regimes. Interestingly, we see that the incentive effects in the later years appear to be driven by the arguably most positively selected group of untenured teachers, those who were placed on the tenure track at initial hire. Starting in 2006, after teachers had witnessed a large number of their peers being dismissed, absences fell by .5 to .7. This suggests that the policy may well have had a modest but non-trivial incentive impact on this group of teachers. The policy did not appear to have any impact on temporarily-assigned teachers (column 2). The coefficient on prior dismissal is large, negative and highly significant for both groups.

To summarize, the results in Tables 6 and 7 suggest that the policy operated through different channels for different groups. For those untenured teachers who were likely the most negatively selected (Groups 1 and 4), the policy appears to have reduced absences by shifting the composition of the group through voluntary attrition of the least productive members of these groups. For the more positively selected untenured teachers, the policy did not lead to any 
compositional changes (at least any that were correlated with absences) but does appear to have had modest incentive effects in the later years.

Table 8 shows how the effect of the policy varies by school characteristics. The first thing to see is that the impact was roughly 2.5 times larger in elementary schools than in high schools. Moreover, there was significantly more variation in the policy effect across high schools than across elementary schools. In elementary schools, for example, the impacts were roughly equivalent in higher- and lower-performing schools (columns 2-3) and across predominantly Hispanic, predominantly African-American and racially mixed elementary schools (columns 4-6). In high schools, by contrast, the effects were concentrated in lowachieving and predominantly African-American schools. In results not reported here, I find that the policy effects in high schools (but not elementary schools) were concentrated in schools with younger principals (i.e., under the age of 50). Columns 7-9 show results separately for schools where a greater or lesser proportion of teachers were untenured, but finds little difference across these groups.

Table 9 shows results separately for various teacher subgroups. Interestingly, the policy seems to have had a significantly higher impact on younger and female teachers, particularly in elementary schools. Given that females had higher rates of absenteeism prior to the introduction of the policy, it may be the case that the policy reduced absences among those at highest risk of absenteeism. To explore this more formally, I predict absence rates based on observable teacher, principal and school characteristics using the pre-reform data, and then estimate the policy effects separately for the top, middle and bottom third of the predicted teacher absence 
distribution. As expected, the policy had a significantly larger impact on teachers with moderate- and high-predicted absences relative to those with low predicted absences. ${ }^{42}$

\subsection{Impacts on Student Achievement}

As noted earlier, the CPS data does not have the information necessary to link individual teachers to students over the analysis period, which precludes examining the impact of the policy on student achievement using the strategy described above. Instead, I estimate a difference-indifference model at the school-year level, comparing within-school changes in student achievement over time between schools with higher versus lower fractions of probationary teachers at the time the policy was implemented. The intuition behind this approach is that schools with a higher fraction of probationary teachers in 2005 experienced a larger "dose” of the treatment. For example, if the policy induces effort among teachers at risk of dismissal, then these schools should experience greater increases in effort, ceteris paribus. Similarly, these schools have the potential to undergo greater turnover, thus realizing greater compositional changes.

To illustrate the intuition behind this strategy, Figures 7 and 8 plot the standardized math and reading scores for 2003 through 2008 separately for elementary schools with the highest and lowest fractions of untenured teachers in 2005. Looking first at all elementary schools in panel A, we see some evidence that achievement increased in schools with a higher fraction of untenured teachers relative to schools with a lower fraction of untenured teachers. When we focus on low-achieving schools in Panel B, however, this pattern is much more evident. This figure suggests that schools with a high fraction of untenured teachers experienced more rapid

\footnotetext{
${ }^{42}$ The on-line appendix includes a table showing how policy effects vary based on the teacher's predicted probability of dismissal. I find that some evidence of larger effects among elementary teachers more likely to be dismissed, although the estimates are not particularly precise.
} 
growth in student achievement following the introduction of the dismissal policy, relative to schools with a lower share of untenured teachers. The reading trends in Figure 8 tell a similar story.

However, the trends in Figures 7 and 8 do not control for any student or teacher characteristics. One obvious concern with this strategy is that the fraction of untenured teachers in a school in 2005 is likely correlated with other factors (both observable and unobservable) that might influence subsequent achievement. To account for this, I estimate the following model:

$$
\begin{gathered}
Y_{s t}=\beta_{0}+\beta_{1}(\% \text { untenured } 05)+\beta_{2}(\text { post })+\beta_{3}(\text { post } * \% \text { untenured } 05)+ \\
\beta_{4}(\% \text { lowinc } 05)+\beta_{4}(\text { post } * \% \text { lowinc } 05)+Z_{\text {st }}+\gamma_{t}+\lambda_{s}+\varepsilon_{\text {st }}
\end{gathered}
$$

where $Y_{s t}$ is a measure of student achievement in school $s$ in year $t{ }^{43}$ The model includes (a) school fixed effects $\lambda_{s}$ (which control for any such time-invariant school characteristics that might be associated with initial teacher experience levels and subsequent student achievement such as a particularly dangerous neighborhood or aging school facilities), (b) time-varying student characteristics $Z_{s t}$ and (c) time-varying measures of teacher experience, also included in $Z_{s t}{ }^{44}$ The teacher experience measures are important because of the well-established experienceeffectiveness gradient in teaching, coupled with the fact that schools with more probationary teachers in 2005 will, by definition, have more teachers progressing through their early teaching years over the period. In addition, I control for an interaction between the fraction low-income in 2005 and a post-policy indicator to account for the fact that schools with a disproportionate

\footnotetext{
${ }^{43}$ The achievement measures used in this analysis come from the Illinois Standards Achievement Test (ISAT), which was the primary standardized exam given to students in Illinois. Because in the earlier years of the period the exam was only administered to students in grades 3,5 and 8, we limit the analysis to these grades. Specifically, we take the school-grade-year average scale scores, standardize these to have mean zero and standard deviation one, and then create an average standardized measure for each school-year weighting by the number of students tested in a particular school-grade-year. For the proficiency outcomes, we simply use the weighted average of the fraction proficient (or higher) in the school-year, again weighting by the number of tested students in each school-gradeyear.

${ }^{44}$ Time-varying covariates include fraction Black, fraction Hispanic, fraction eligible for free lunch, teacher experience and its square and the fraction of teachers with less than 3 years of experience.
} 
number of untenured teachers also have a more disadvantaged student population, and achievement may have changed in low-income schools for reasons unrelated to the dismissal policy. The coefficient on the interaction between post and \%untenured05, $\beta_{3}$, measures the achievement effect of the policy. ${ }^{45}$

Table 10 shows estimates corresponding to equation (1.3) where the regressions are weighted by student enrollment and standard errors are clustered by school. The top panel shows results using the school average scale score in math as the outcome, standardized using the standard deviation in school mean scores (as opposed to the student-level standard deviation). Focusing first on elementary school results in columns 1-3, one sees that the point estimate of .24 (column 1) is marginally significant, and is driven by the effects in low-achieving schools (column 2). The implied effect is quite large. Given that the student standard deviations are roughly double the standard deviation in school means, if we assume zero spillovers from untenured to tenured teachers, these results suggest an effect size of roughly .5 student standard deviations among "treated” (i.e., untenured) teachers. Equivalently, the point estimates suggest that a 30-percentage point increase in the fraction of untenured teachers at the school would be associated with an increase in student achievement of $.3 \times .5=.15$ standard deviations. The results for other outcomes - average reading achievement, the fraction proficient in math, fraction proficient in reading - are comparable.

\footnotetext{
${ }^{45}$ In order for this strategy to provide reliable results, there must be substantial variation in the school fraction of untenured teachers across schools that have similar poverty and/or achievement levels. Fortunately, this appears to be the case. For elementary schools, the mean within school percent probationary (untenured) teachers in 2005 was $33 \%$ (43\%), the 90th percentile was 50\% (65\%) and the 10th percentile was $19 \%$ (26\%). Importantly, the fraction untenured in a school in 2005 was only modestly correlated with student demographics (correlation of .2 with fraction eligible for free-lunch) and student achievement (correlation of -.29 with fraction meeting proficiency standard). This suggests that there will be substantial variation in probationary status that is not correlated with other observable school characteristics to allow independent identification of $\beta_{3}$ and $\beta_{5}$ above.
} 
In contrast, we see no significant effects of the policy on student achievement in high schools. Moreover, it is important to note that even the elementary school results are somewhat sensitive to the model specification. In particular, models that use the fraction probationary rather than the fraction untenured produce somewhat smaller point estimates that are not significantly different than zero. ${ }^{46}$ And, yet, the point estimates themselves are still quite large from an economic standpoint. Based on estimates of the relationship between teacher absences and student achievement from other studies, the observed decline in teacher absences can only explain a tiny fraction of the teacher effort response. ${ }^{47}$ In summary, there is suggestive evidence of sizeable achievement effects among elementary school students, although this finding should be taken with some caution.

\section{Conclusions}

In this paper, I take advantage of a unique policy change in the Chicago Public Schools (CPS) to estimate the effect of employment protection on worker effort. My results suggest that the reduction of job security for probationary teachers in Chicago led to a 10-25 percent reduction in teacher absenteeism. The majority of the effect was due to changes in the composition of teachers in the district, although there is evidence of modest incentive effects for

\footnotetext{
${ }^{46}$ On the other hand, none of the estimates presented here is sensitive to the student enrollment weighting or the use of the natural logarithm of achievement (or the log odds of fraction proficient) as the outcome.

${ }^{47}$ Column 2 of the top panel in Table 10 indicates that a 30-percentage point increase in fraction untenured is associated with approximately $0.3 \times 0.3=0.09$ fewer absences. Prior research suggests that a reduction of 1 teacher absence increases student achievement by about 0.002 student standard deviations (Clotfelter et al. 2007, Miller et al. 2007). Hence if achievement were operating solely through reduced teacher absence, then one would expect a 30 -percentage point increase in the fraction untenured to result in a $0.09 \times 0.002=0.00018$ student standard deviation gain in achievement. The estimates in Table 10 are measured in terms of school-level standard deviations, which are roughly half the size of the student-level standard deviation in Chicago elementary schools during this period. For example, in 2006, the student s.d. of reading scores in grades 3, 5 and 8 was roughly 29, 28 and 23 compared with the school s.d. of 13, 13 and 10 . In math, the corresponding figures are 29, 27 and 26 compared with 15, 14 and 13. Hence, the point estimate of 0.329 school-level s.d. in column 2 of the top panel corresponds to an effect of 0.329 x $2 \sim 0.66$. A 30 pp effect would be 0.3 x $0.66 \sim 0.20$. Hence, teacher absences can only explain roughly $0.00018 / 0.20=0.0009$, less than 1 percent, of the effect of the policy.
} 
younger untenured teachers. The effects were strongest among teachers in elementary schools and teachers with high predicted absences.

The findings presented here have important implications for current education policy debates. Specifically, the decline in teacher absenteeism following the introduction of the policy provides the most compelling evidence to date that change in teacher contract provisions can improve student outcomes. At the same time, the apparent reluctance of many principals to utilize the additional flexibility granted under the new contract in Chicago speaks to the potential importance of teacher supply and/or social norms governing employment relations in schools. This suggests that contractual changes alone will not be sufficient to change the practice of promotion and tenure in teaching. 


\section{References}

Thomas Ahn (2011). “The Missing Link: Estimating the Impact of Incentives on Effort and Effort on Production Using Teacher Accountability Legislation.” Working paper, University of Kentucky.

Autor, David H., John Donohue III, and Stewart J. Schwab, "The Employment Consequences of Wrongful-Discharge Laws: Large, Small, or None at All?” American Economic Review Papers and Proceedings 93:2 (2004), 440-446.

Autor, David, William Kerr and Adriana Kugler (2007). "Do Employment Protections Reduce Productivity? Evidence from U.S. States”, 2007, The Economic Journal, 117 (June), F189-F217.

Autor, David H., John J. Donohue III and Stewart J. Schwab (2006). “The Costs of WrongfulDischarge Laws.” Review of Economics and Statistics 88(2): 211-231.

Ballou, D. (2000). Teacher Contracts in Massachusetts. Boston, MA: Pioneer Institute for Public Policy.

Bertola, Giuseppe. 1990. Job security, employment, and wages. European Economic Review 34, no. 4:851-79.

Bertrand, M., Duflo, E., Mullainathan, S. (2004). How Much Should We Trust Differences-in Differences Estimates? Quarterly Journal of Economics 2004; 119(1), 249-75.

Besley, Timothy, and Robin Burgess. 2004. Can labor regulation hinder economic performance? Evidence from India. Quarterly Journal of Economics 119, no. 1:91-134.

Bird, R. and Knopf, J. (2009). ”Do wrongful discharge laws impair firm performance?” The Journal of Law and Economics, 52(May).

BLS (2012) "Bureau of Labor Statistics, U.S. Department of Labor, Economic News Release, accessed on 02/14/2012 [ http://www.bls.gov/news.release/jolts.t09.htm ]."

Bradley, Steve, Colin Green, and Gareth Leeves. 2007. "Worker Absence and Shirking:

Evidence from Matched Teacher-School Data." Labour Economics, 14(3), 319-34.

Bauer, Thomas, Stefan Bender and Holger Bonin. 2007. Dismissal Protection and Worker Flows in Small Establishments. Economica 74: 804-821.

Cameron, A. Colin, Jonah. B. Gelbach and Doug Miller (2008). “Bootstrap-Based Improvements for Inference with Clustered Errors,” Review of Economics and Statistics, Vol. 90, No 3, 2008, pages 414-427.

CTU 1999. Agreement between the Board of Education of the City of Chicago and Chicago Teachers Union Local 1, AFL-CIO, July 1, 1999 - June 30, 2003. 
Clotfelter, C.T., H.F. Ladd, and J.L. Vigdor (2009) “Are Teacher Absences Worth Worrying About in the U.S.?” Education Finance and Policy v.4 n.2 pp.115-149.

Donald, Stephen G., and Kevin Lang (2007). "Inference with Difference-in-Differences and Other Panel Data,” Review of Economics and Statistics 89(2), 2007, pages 221-233.

Duflo, E., \& Hanna, R. (2006). Monitoring Works: Getting Teachers to Come to School:

C.E.P.R. Discussion Papers CEPR Discussion Papers: 5426.

Dee, T.S. and Jacob, B.A. (2009). “The Impact of No Child Left Behind on Student Achievement.” NBER Working Paper \#15531.

Educational Research Service. 1980. "Employee Absenteeism: A Summary of Research," Arlington, VA: Educational Research Service.

Ehrenberg, Ronald G., Randy A. Ehrenberg, Daniel I. Rees, and Eric L. Ehrenberg. 1991. "School District Leave Policies, Teacher Absenteeism, and Student Achievement." Journal of Human Resources, 26(1), 72-105.

Fama, Eugene. 1980. "Agency Problems and the Theory of the Firm." The Journal of Political Economy, 88(2), 288-307.

Figlio, D. and with Lawrence Getzler. 2006. Accountability, ability and disability: Gaming the system? In Advances in Microeconomics, Vol. 14: Improving School Accountability - Checkups or Choice?, ed. T. Gronberg and D. Jansen, 35-49. Amsterdam: Elsevier.

Figlio, D., with J. Winicki. 2005. Food for thought? The effects of school accountability plans on school nutrition. Journal of Public Economics 89(2-3): 381-94.

Friesen, Jane. 2005. “Statutory firing costs and lay-offs in Canada”, Labour Economics, 12(2): 147-168.

Hansen, Michael. 2009a. Career concerns incentives and teacher effort. University of Washington Working Paper.

Hanushek, Eric A. (1994). Making Schools Work: Improving Performance and Controlling Costs. Brookings Institution Press, Washington, DC.

Hanushek, Eric A., John F. Kain, Daniel M. O’Brien and Steven G. Rivkin, “The Market for Teacher Quality,” NBER Working Paper No. 11252 (2005).

Eric A. Hanushek, "Assessing the Effects of School Resources on Student Performance: An Update,” Educational Evaluation and Policy Analysis 19(1997): 141-164.

Hanushek, Eric A. and Margaret E. Raymond (2005) "Does School Accountability Lead to Improved Student Performance?” Journal of Policy Analysis and Management 24(2): 297-327. 
Haynes, V. D. (2008, July 3, 2008). Rhee Seeks Tenure-Pay Swap for Teachers. The Washington Post.

Hess, F. M., \& Loup, C. (2008). The Leadership Limbo: Teacher Labor Agreements in America's Fifty Largest School Districts. Washington, D.C.: Thomas B. Fordham Institute.

Holmström, Bengt. 1982. "Managerial Incentive Problems: A Dynamic Perspective," Essays in Economics and Management in Honor of Lars Wahlbeck. Helsinki: Swedish School of Economics. Reprinted in Review of Economic Studies (1999), 66(1): 169-182.

Hopenhayn, Hugo, and Richard Rogerson. 1993. Job turnover and policy evaluation: A general equilibrium analysis. Journal of Political Economy 101, no. 5:915-38

Hoxby, Caroline M. , Editor, (2003). The Economics of School Choice. University of Chicago Press. Chicago.

Hunt, Jennifer. 2000. "Firing Costs, Employment Fluctuations, and Average Employment: An Examination of Germany”, Economica, 67(266):177-202.

Ichino A., Riphahn R., "The Effect of Employment Protection on Worker Effort. A Comparison of Absenteeism During and After Probation.”, Journal of the European Economic Association, March 2005, 3(1): 120-143.

Jackson, Kirabo C. and Elias Bruegmann (2009). "Teaching Students and Teaching Each Other: The Importance of Peer Learning for Teachers.” American Economic Journal: Applied Economics, 1(4): 1-27.

Jacob, Brian (2005) "Accountability, Incentives and Behavior: the Impact of High-Stakes Testing in the Chicago Public Schools.” Journal of Public Economics 89(5-6): 761-796.

Jacob, Brian A. (2011). “Do Principals Fire the Worst Teachers?” Educational Evaluation and Policy Analysis. 33( 4): 403-434.

Jacob, Brian and Elias Walsh (2011). "What's in a Rating?” Economics of Education Review. 30(3): 434-448.

Jacob, Brian, Lars Lefgren and David Sims (2010). “The Persistence of Teacher Effects.” Journal of Human Resources. 45(4): 915-943

Jovanovic, Boyan (1979). “Job Matching and the Theory of Turnover.” Journal of Political Economy, 87(5): 972-990.

Kane, Thomas, Jonah E. Rockoff and Douglas O. Staiger (2009), "What Does Certification Tell Us About Teacher Effectiveness? Evidence from New York City,” Economics of Education Review, 27(6): 615-631.

Kugler, Adriana D. (1999). “The Impact of Firing Costs on Turnover and Unemployment: 
Evidence from the Colombian Labour Market Reform.” International Tax and Public Finance, 6, 389-410.

Kugler, Adriana, Giovanni Pica. 2008. Effects of Employment Protection on Job and Worker Flows: Evidence from the 1990 Italian Reform, Labour Economics 15(1): 78-95.

Lavy, Victor (2007). “Using Performance-Based Pay to Improve the Quality of Teachers”, The Future of Children, Spring 2007, 87-110.

Lazear, Edward P. 1990. Job security provisions and employment. Quarterly Journal of Economics 105, no. 3:699-726.

Marinescu, Ioana (2009). "Job Security Legislation and Job Duration: Evidence from the United Kingdom.” Journal of Labor Economics, 27(3): 465.

Martins, Pedro S. (2009). "Dismissals for Cause: The Difference that Just Eight Paragraphs Can Make.” Journal of Labor Economics 27(2): 257-279.

Miller, Reagen T., Murnane, Richard J. and John B. Willet (Forthcoming). "Do Worker Absences Affect Productivity? The Case of Teachers.” International Labor Review.

Neal, Derek A. and Diane Schanzenbach (Forthcoming). "Left Behind by Design: Proficiency Counts and Test-Based Accountability.” Review of Economics and Statistics.

Petrin, A. and Sivadasan, J. (2006). "Job security does affect economic efficiency: theory, a new statistic, and evidence from Chile”, NBER Working Paper 12757.

Podgursky, M. and Springer, M.G. (2007). “Teacher Performance Pay: A Review.” Journal of Policy Analysis and Management, 26(4).

Prendergast, Canice (1999). “The Provision of Incentives in Firms.” Journal of Economic Literature, 37(1): 7-63.

Price, M. (2009). Teacher Union Contracts and High School Reform. Seattle, WA: Center on Reinventing Public Education.

Rockoff, Jonah E. 2004. "The Impact of Individual Teachers on Students' Achievement: Evidence from Panel Data." American Economic Review, 94(2), 247-52. 
Figure 1: Time Trend of Teacher Absences by Status, All Schools

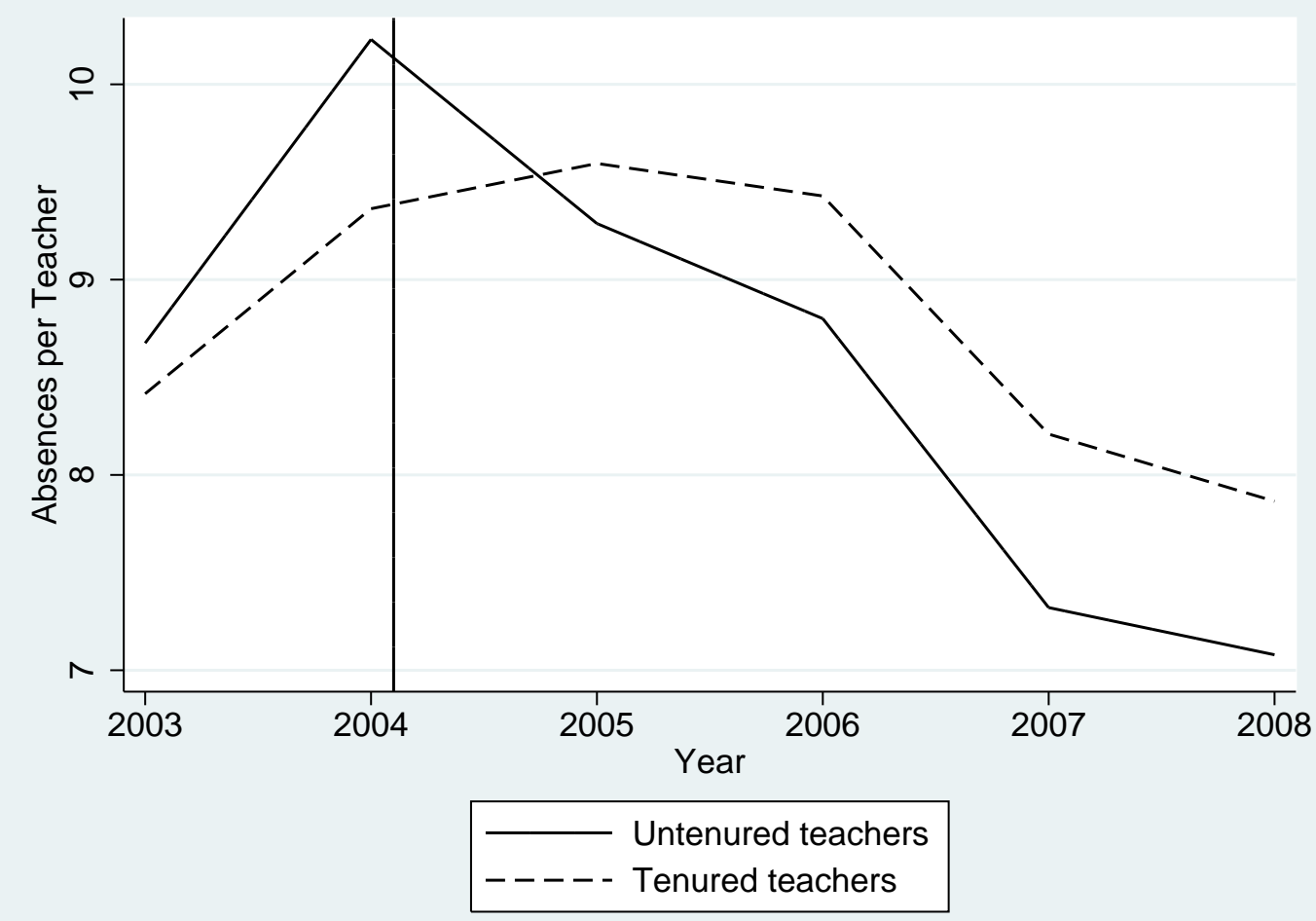

(a) Absences per Teacher

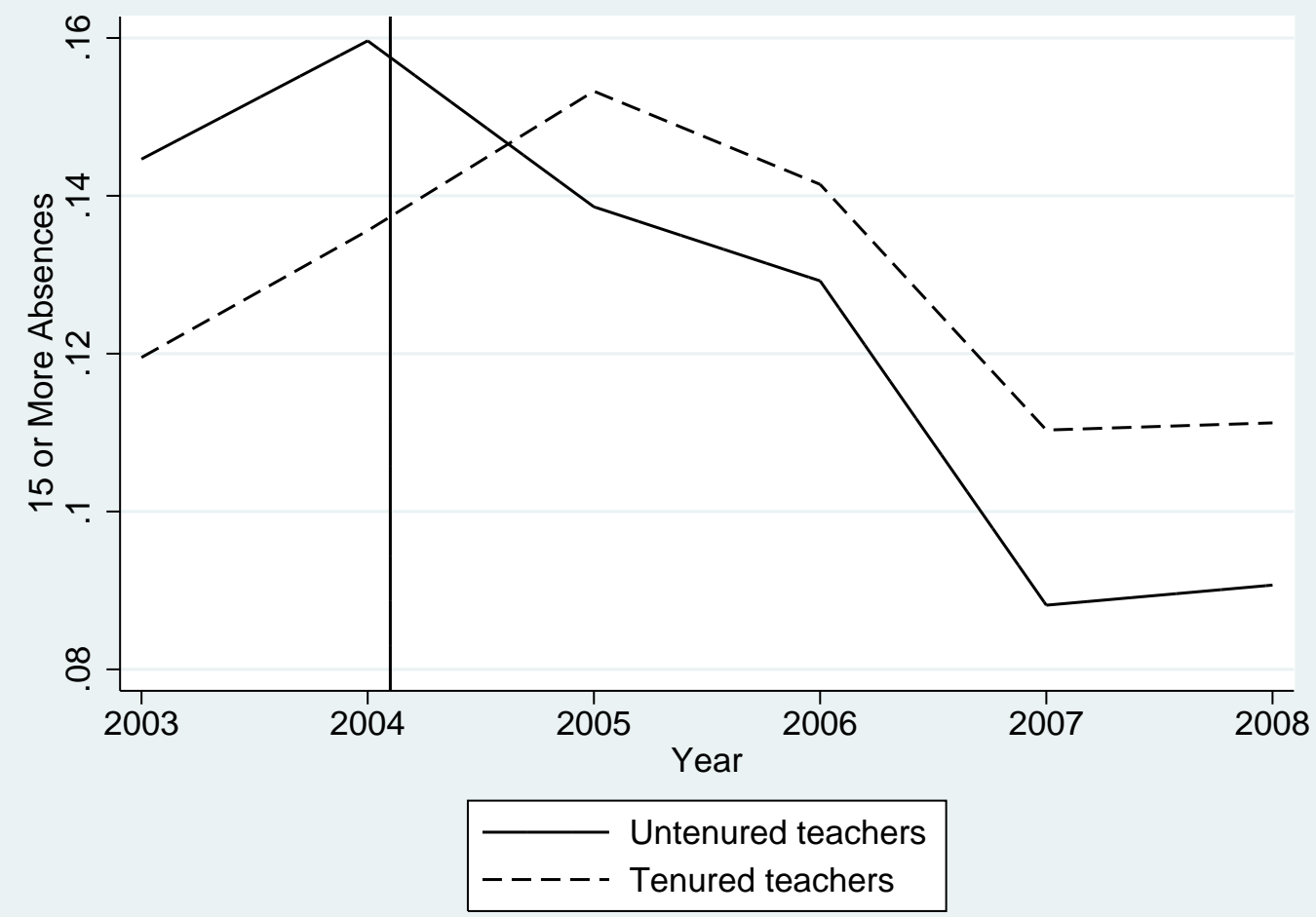

(b) Fraction of Teachers with 15 or more Absences 
Figure 2: Time Trend of Teacher Absences by Status, Elementary Schools
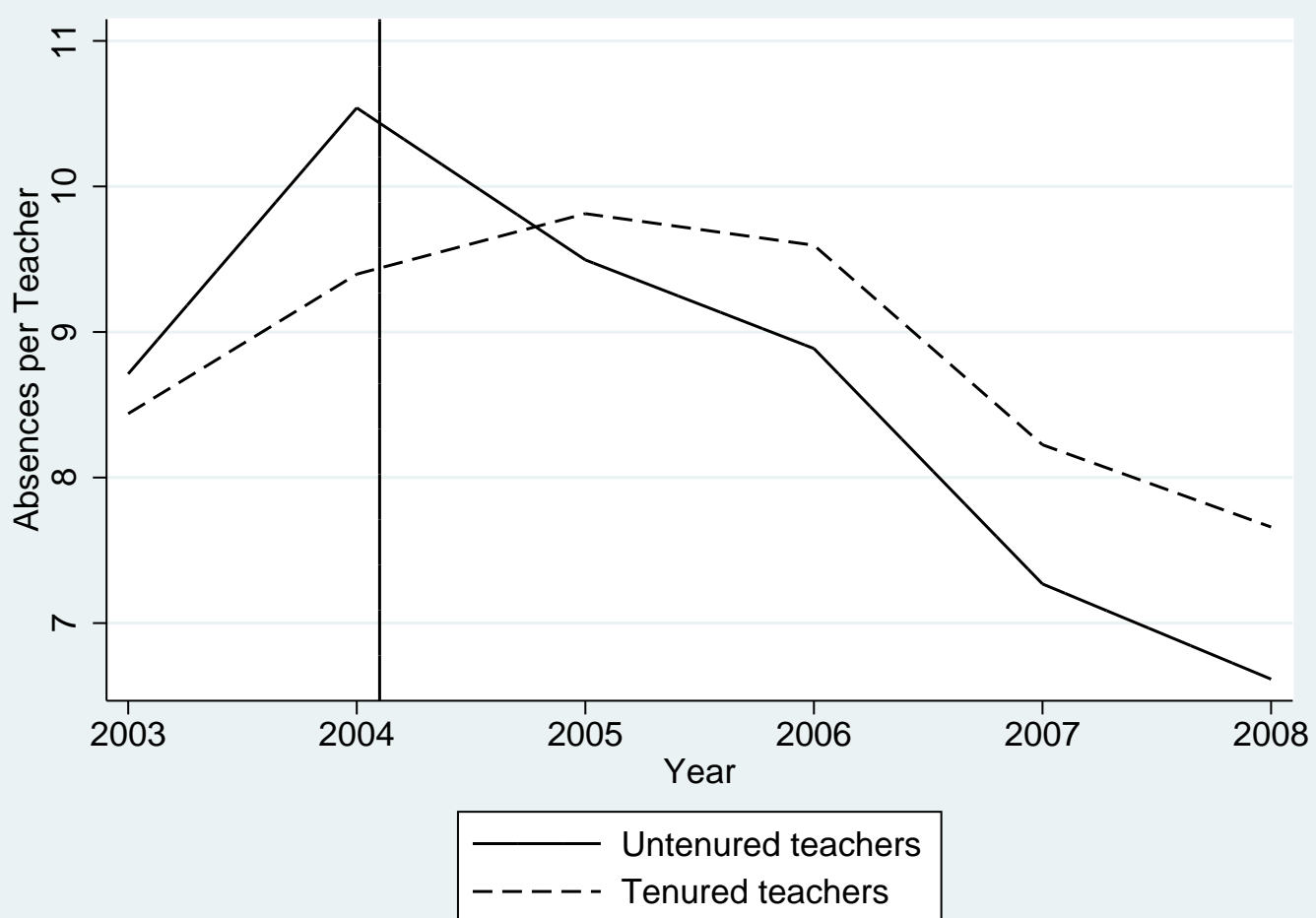

(a) Absences per Teacher

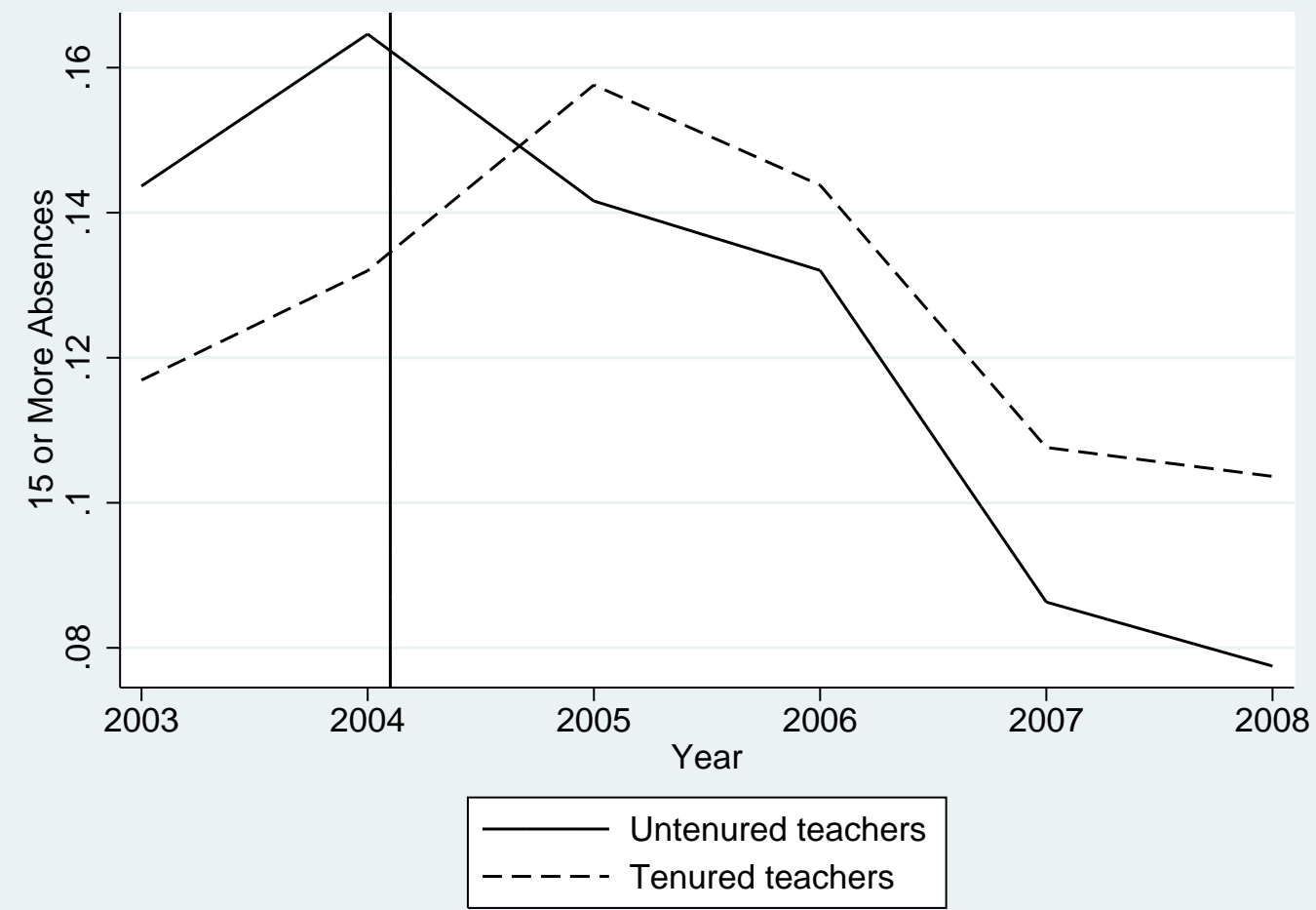

(b) Fraction of Teachers with 15 or more Absences 
Figure 3: Time Trend of Teacher Absences by Status, High Schools

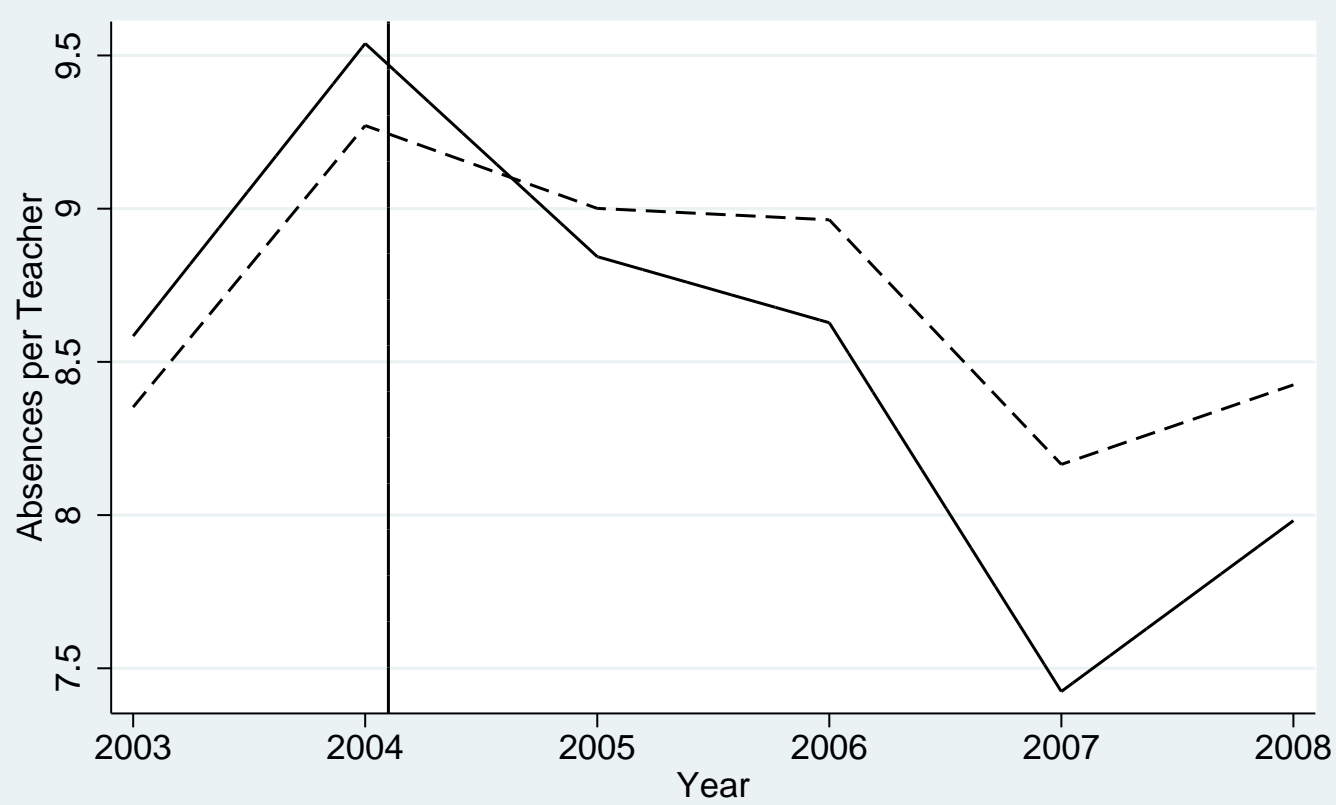

Untenured teachers

- - - - - Tenured teachers

(a) Absences per Teacher

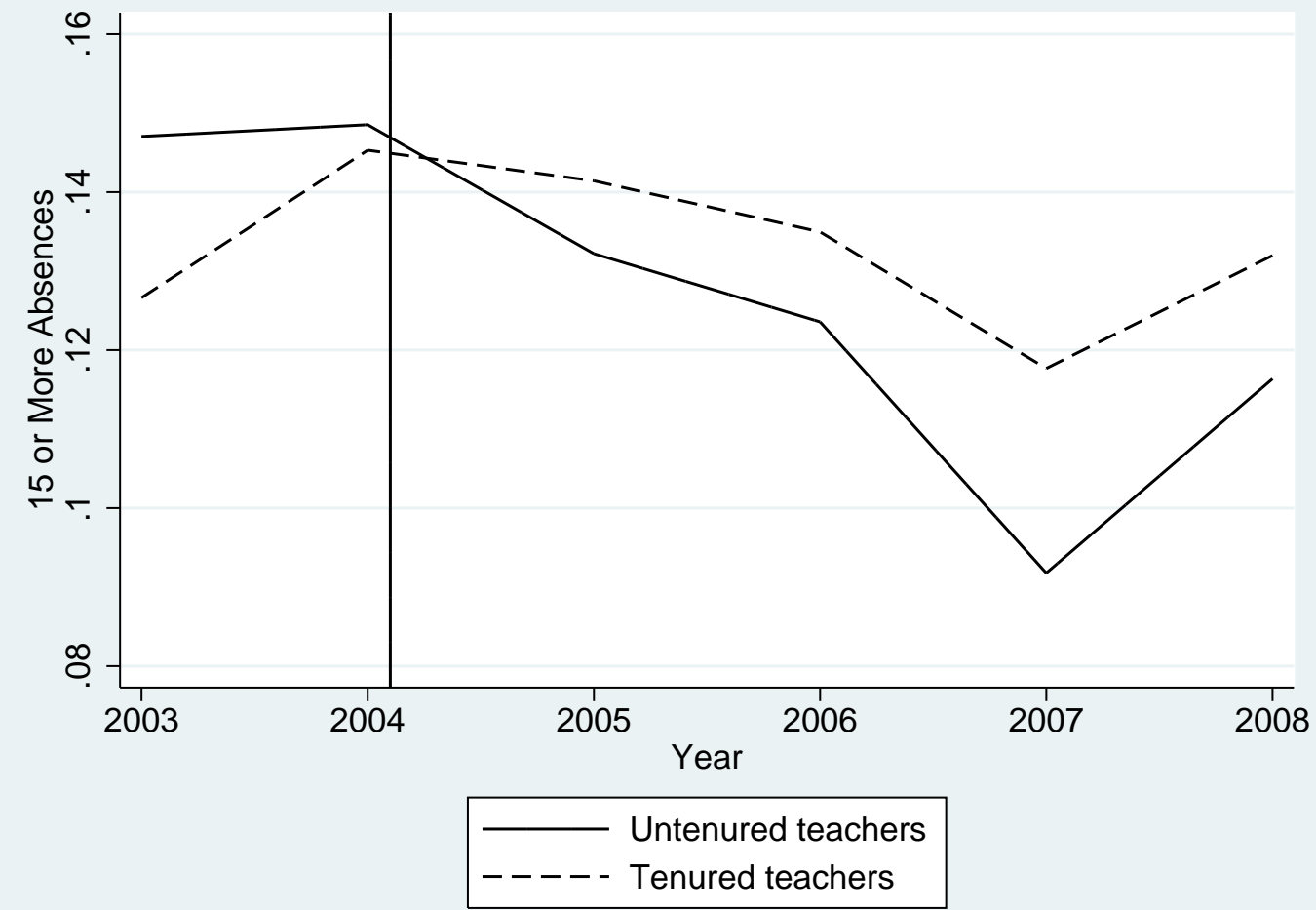

(b) Fraction of Teachers with 15 or more Absences 
Figure 4: Time Trend of Teacher Absences by Experience, All Schools

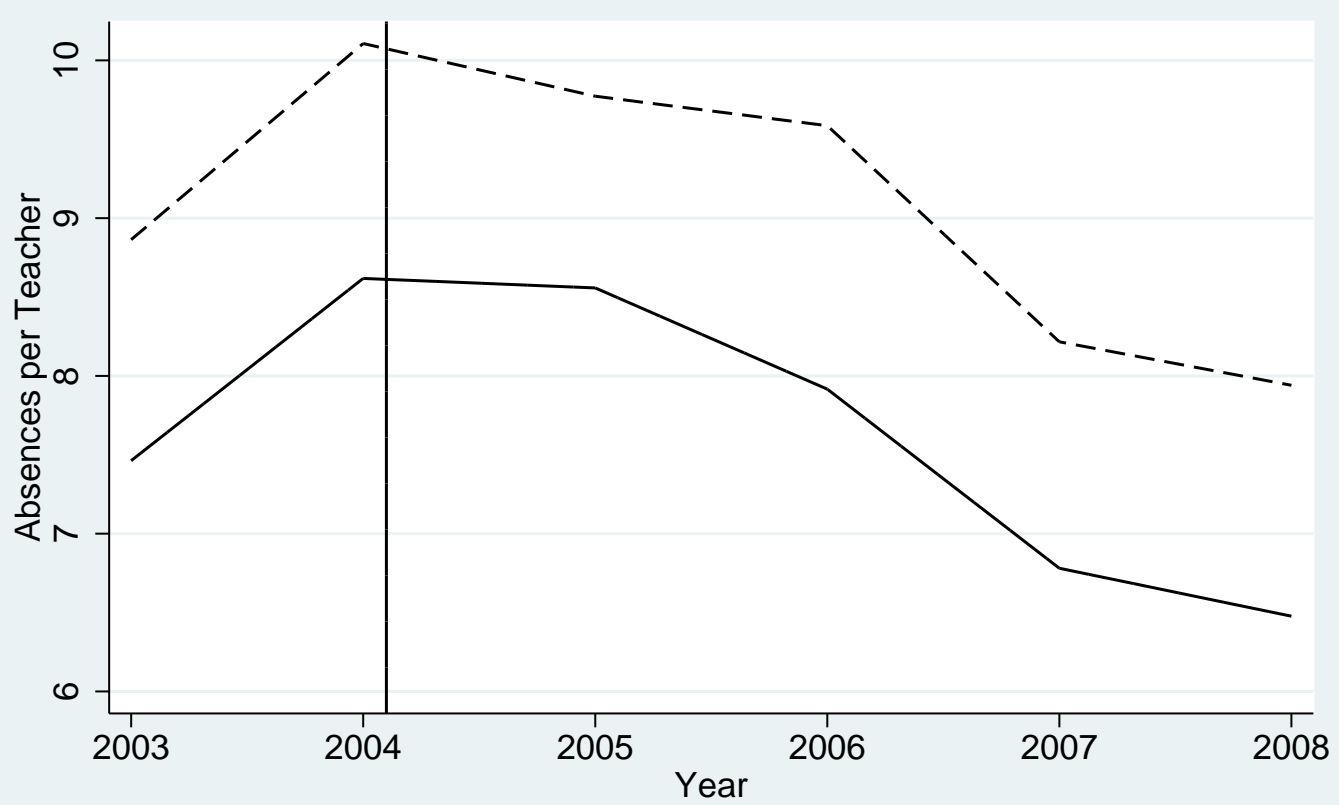

1-4 years experience

-----5 or more years experience

(a) Absences per Teacher

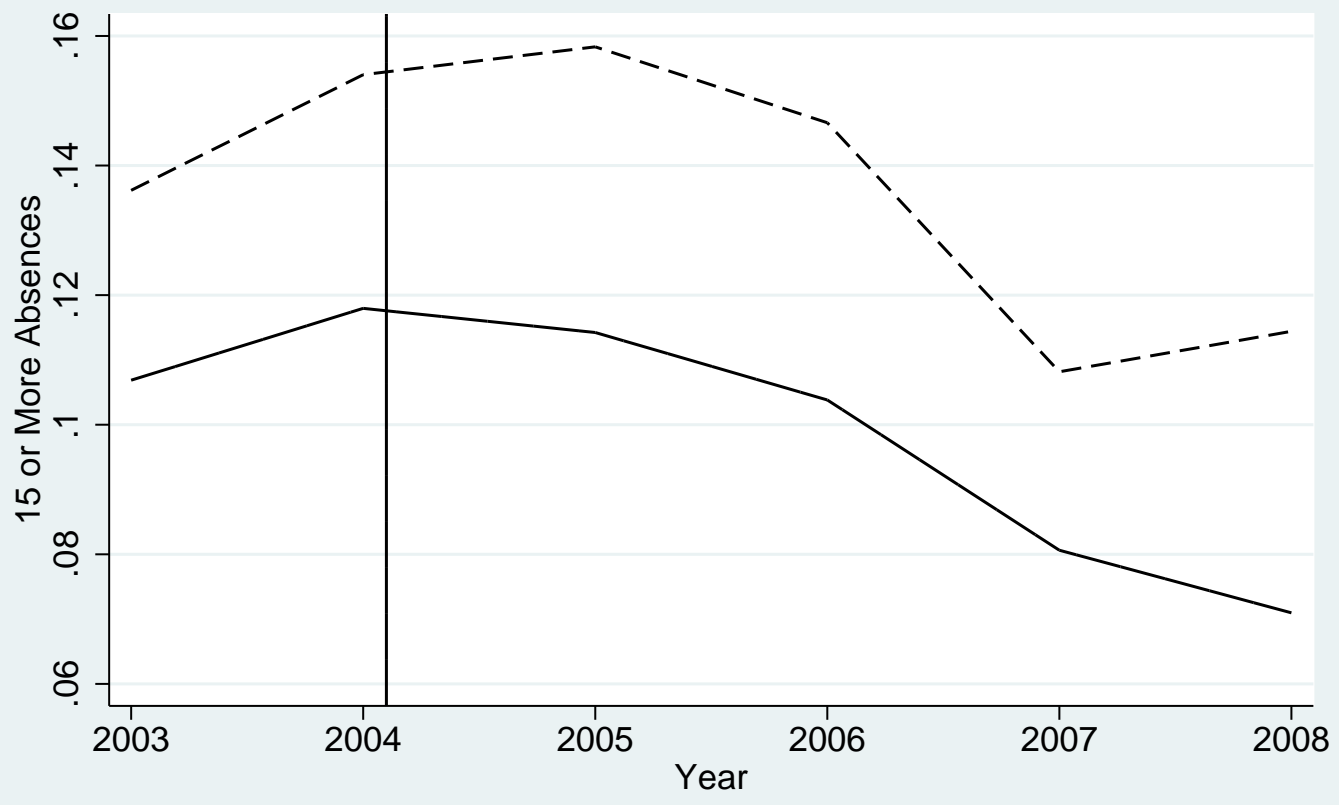

$-1-4$ years experience
-----5 or more years experience

(b) Fraction of Teachers with 15 or more Absences 
Figure 5: Time Trend of Teacher Absences by Experience, Elementary Schools

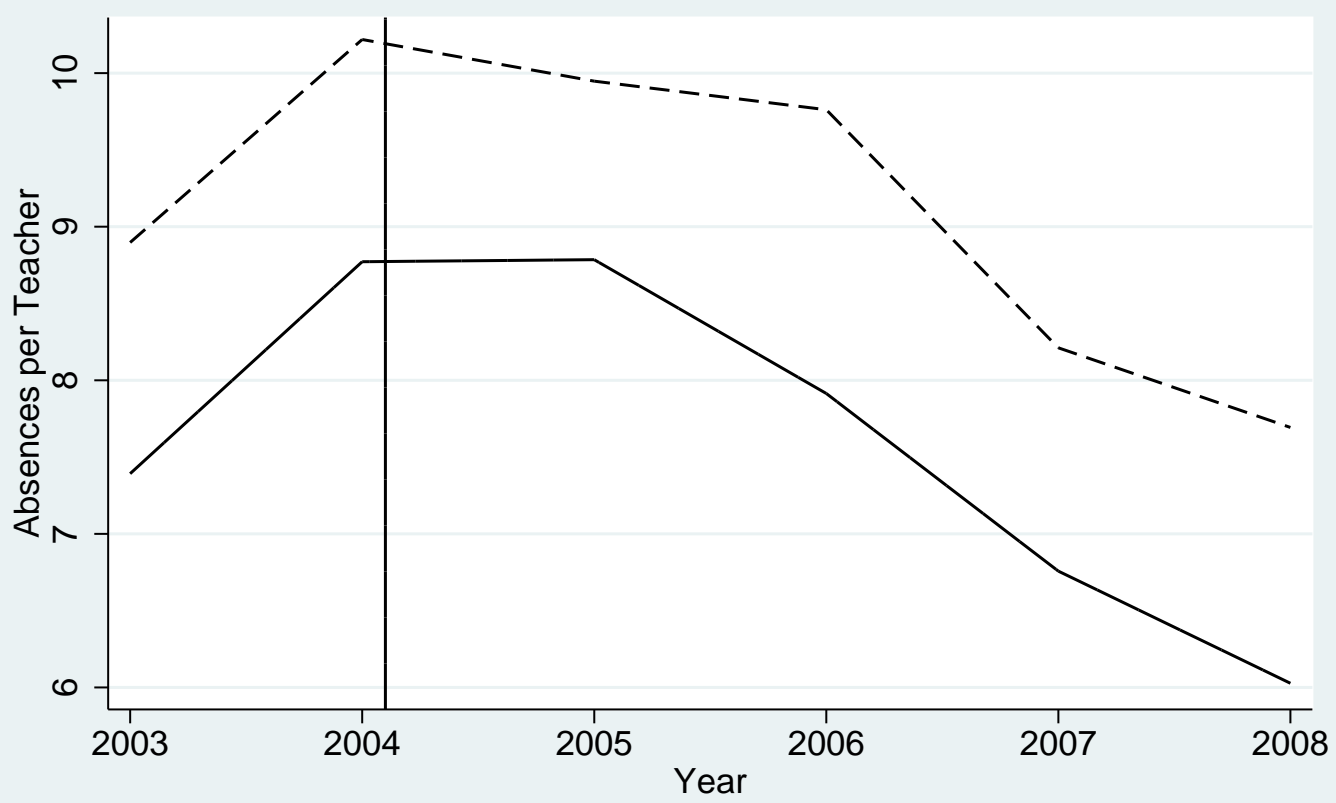

1-4 years experience

-----5 or more years experience

(a) Absences per Teacher

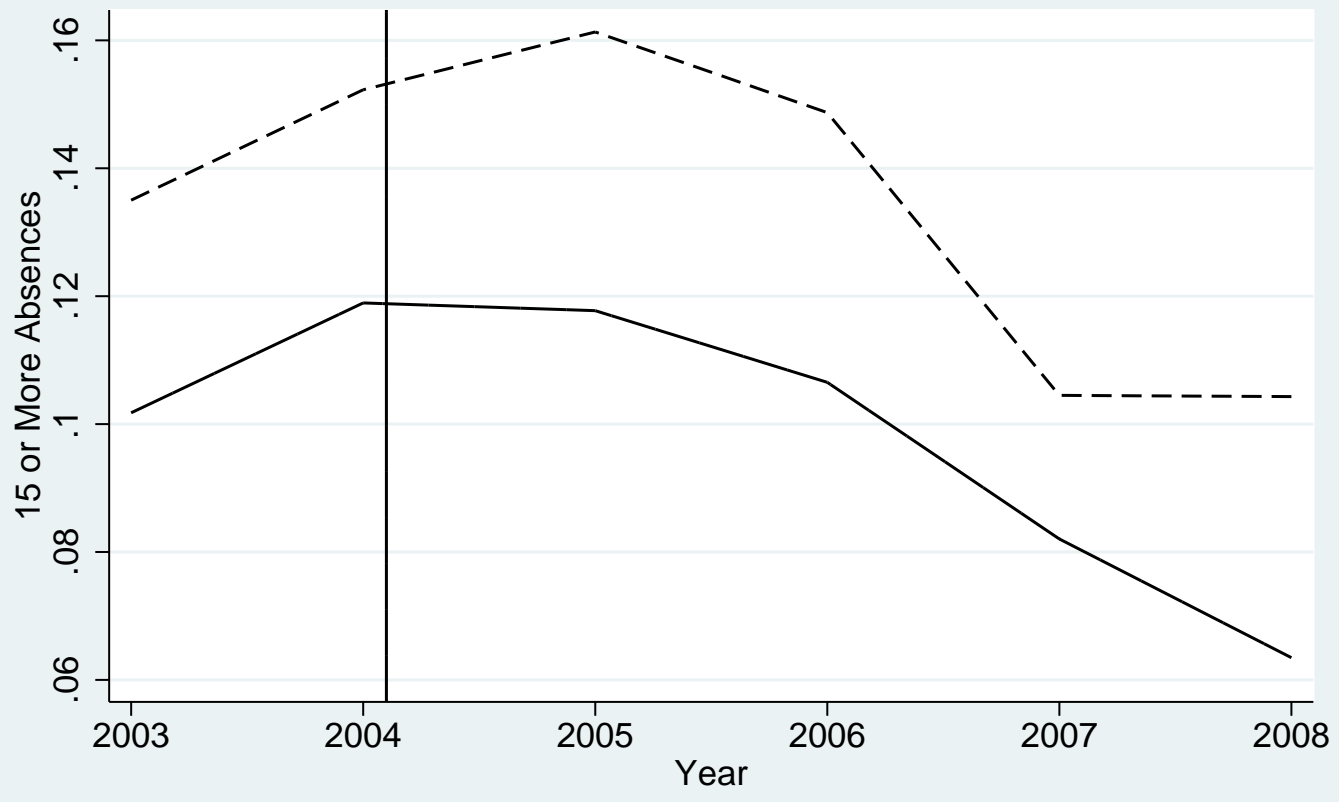

$-1-4$ years experience
-----5 or more years experience

(b) Fraction of Teachers with 15 or more Absences 
Figure 6: Time Trend of Teacher Absences by Experience, High Schools

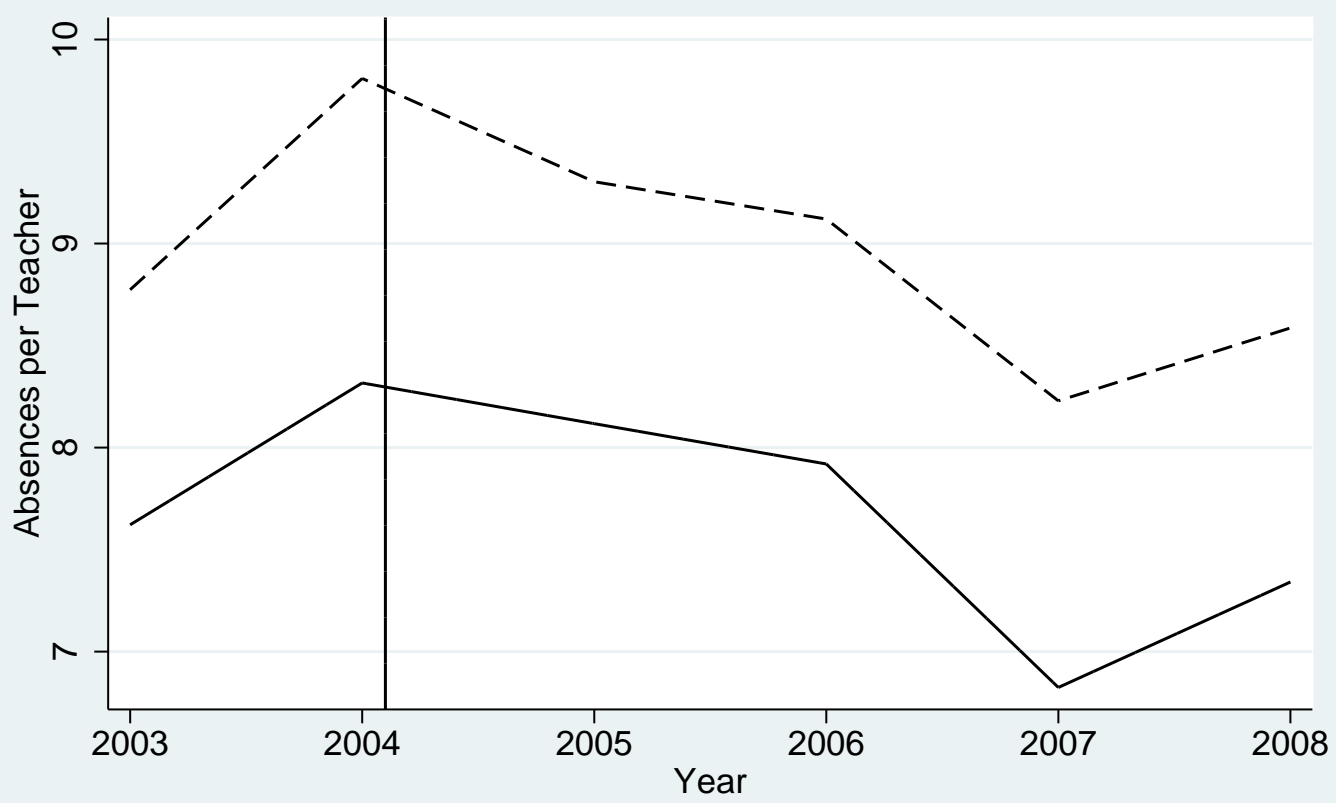

1-4 years experience

-----5 or more years experience

(a) Absences per Teacher

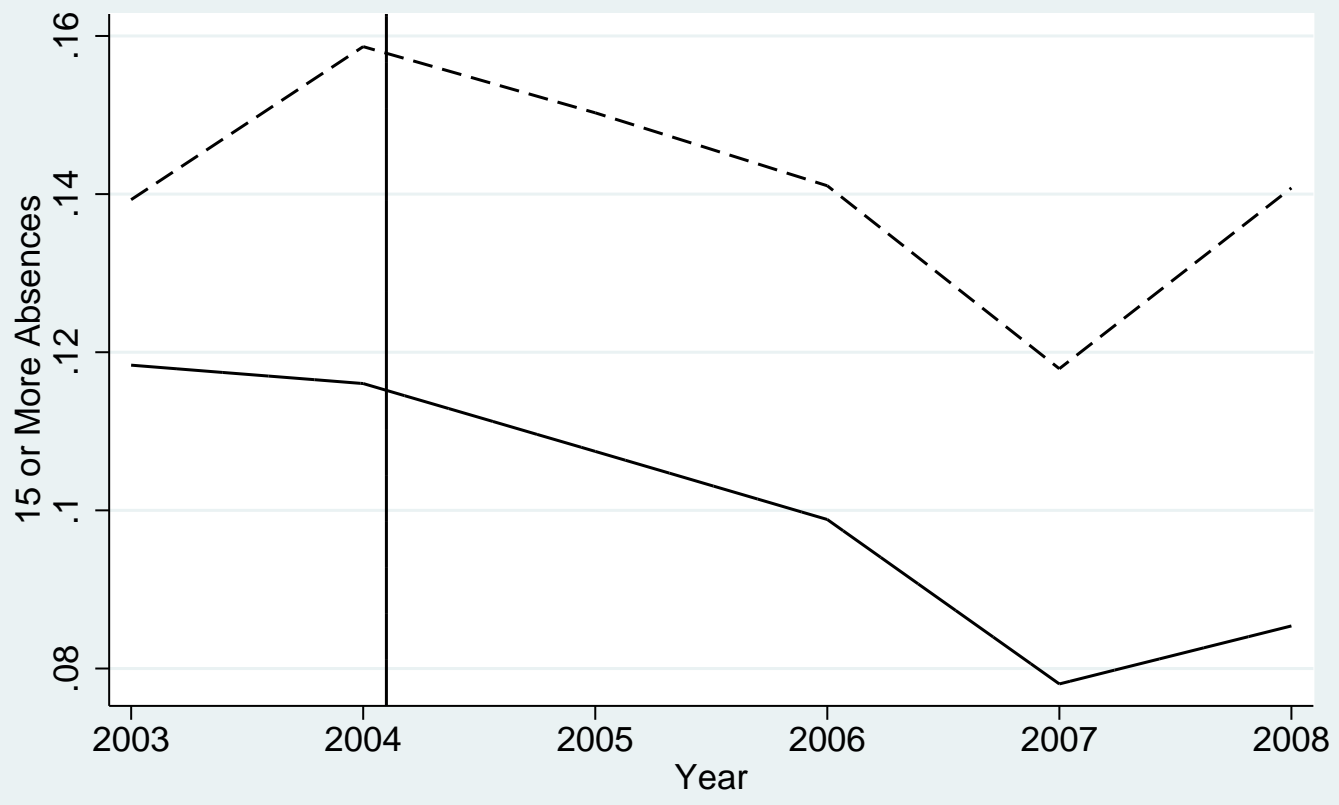

$-1-4$ years experience
-----5 or more years experience

(b) Fraction of Teachers with 15 or more Absences 
Figure 7: Time Trend of School-Level Math Achievement by Fraction Untenured in School in 2005, Elementary Schools

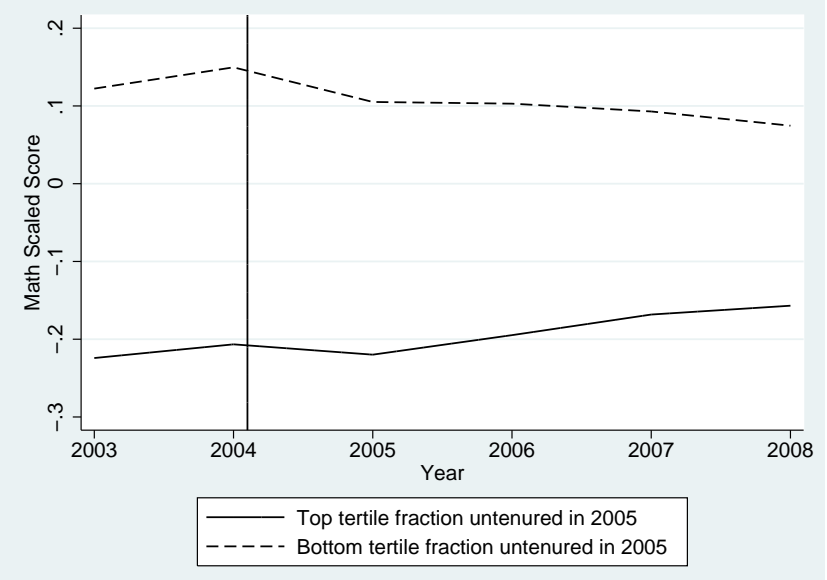

(a) Scaled Scores, All Elementary Schools

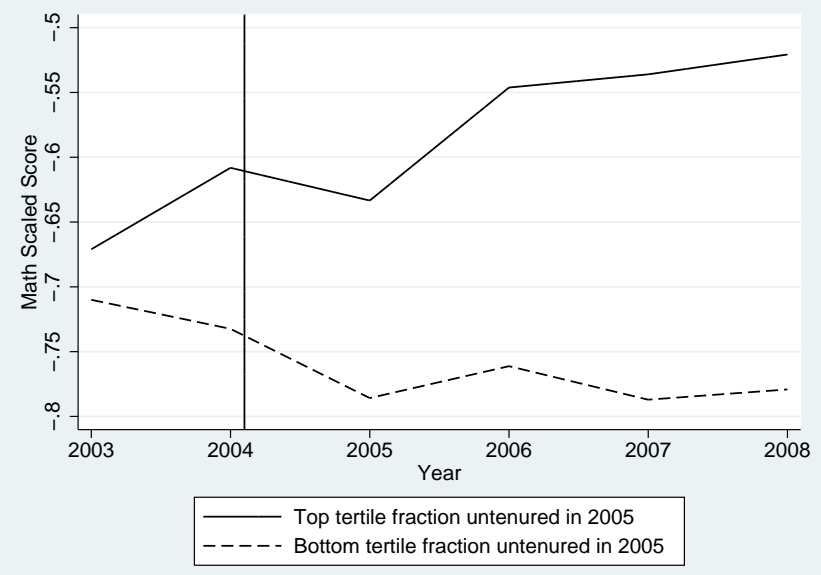

(b) Scaled Scores, Low Achieving Elementary Schools

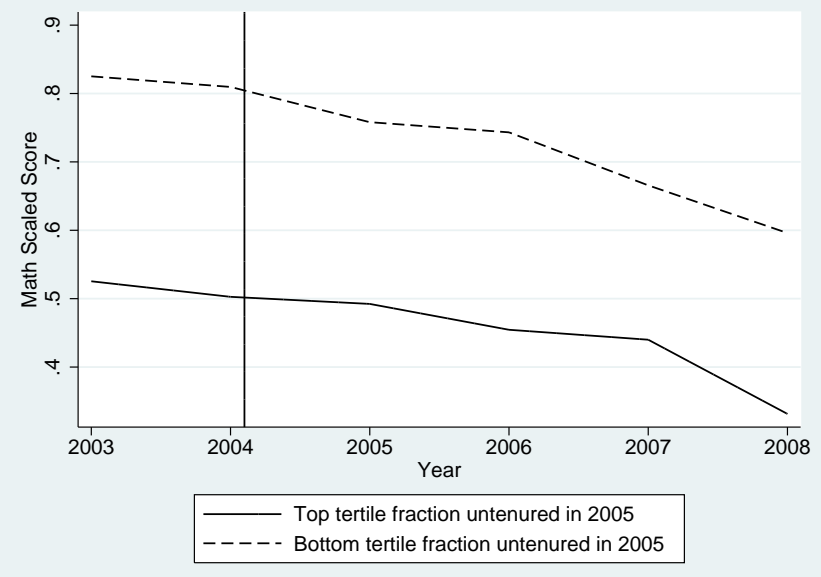

(c) Scaled Scores, High Achieving Elementary Schools 
Figure 8: Time Trend of School-Level Reading Achievement by Fraction Untenured in School in 2005, Elementary Schools

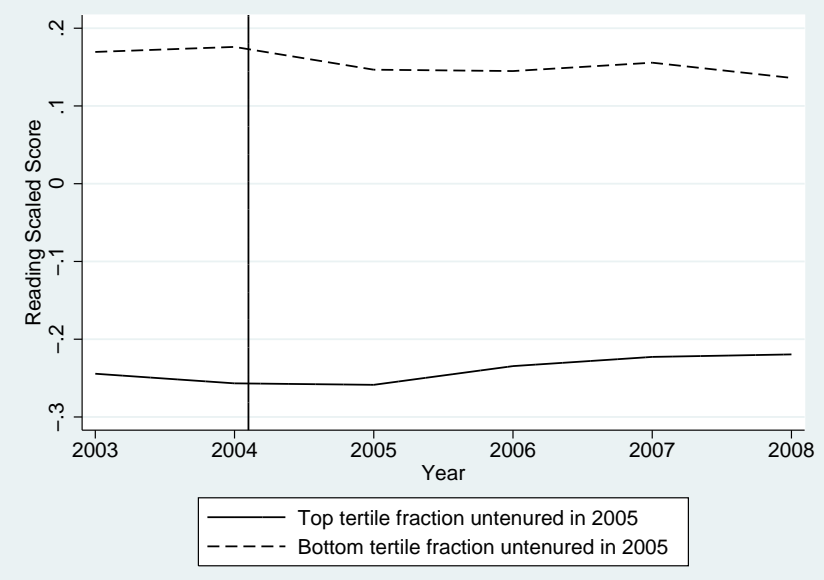

(a) Scaled Scores, All Elementary Schools

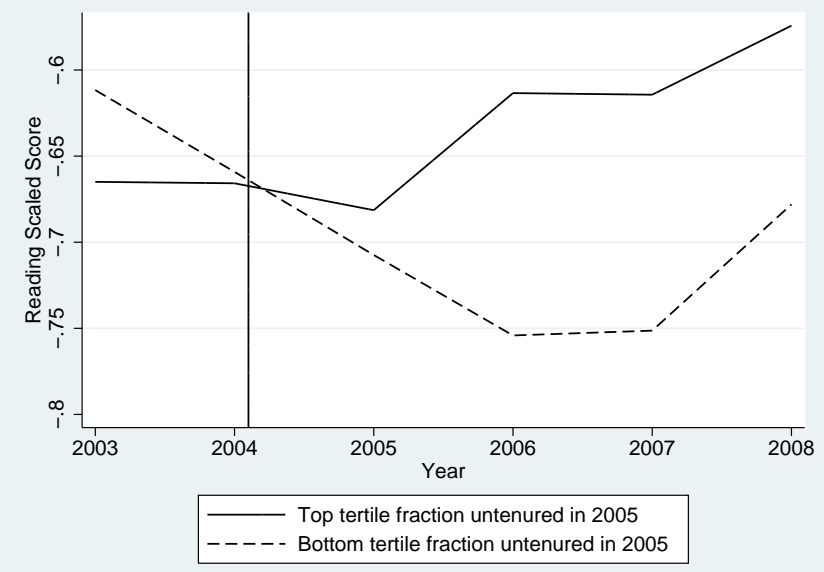

(b) Scaled Scores, Low Achieving Elementary Schools

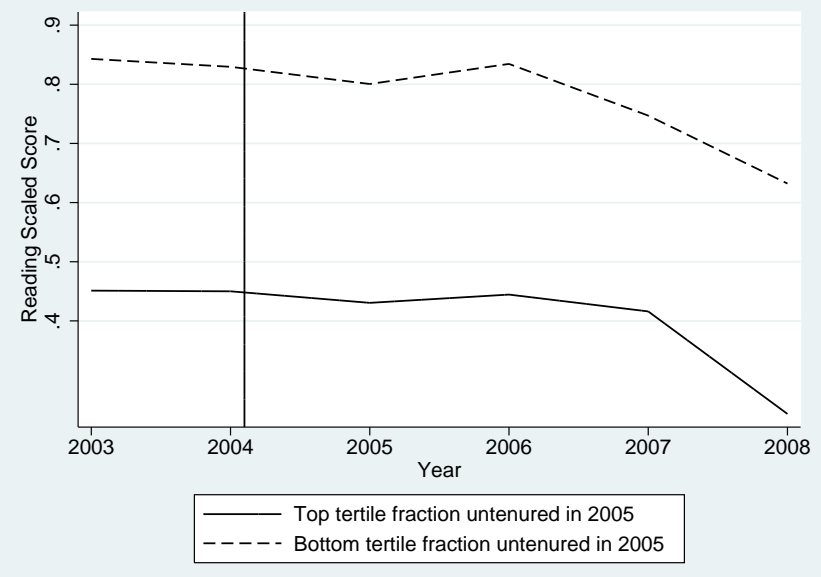

(c) Scaled Scores, High Achieving Elementary Schools 
Table 1 - Summary Statistics on Teacher Dismissal in Chicago

\begin{tabular}{|c|c|c|c|c|c|c|c|c|}
\hline & \multicolumn{4}{|c|}{ Elementary Schools } & \multicolumn{4}{|c|}{ High Schools } \\
\hline & 2005 & 2006 & 2007 & 2008 & 2005 & 2006 & 2007 & 2008 \\
\hline Number of teachers per school & 35.7 & 34.5 & 33.6 & 32 & 68 & 65.6 & 66.6 & 65 \\
\hline Number of probationary teachers per school & 12.3 & 11.6 & 10.8 & 10.3 & 26.9 & 36 & 24.52 & 23.96 \\
\hline Total number of probationary teachers dismissed in the year & 679 & 487 & 692 & 264 & 338 & 278 & 206 & 149 \\
\hline Fraction of probationary teachers dismissed in the year & 0.114 & 0.123 & 0.095 & 0.054 & 0.123 & 0.103 & 0.088 & 0.064 \\
\hline \multicolumn{9}{|l|}{ Fraction of probationary teachers who were dismissed } \\
\hline 4 years experience & 0.074 & 0.100 & 0.073 & 0.053 & 0.120 & 0.109 & 0.100 & 0.084 \\
\hline
\end{tabular}

Notes: Based on author's calculations using CPS administrative data. 
Table 2 - Teacher Separations over Time

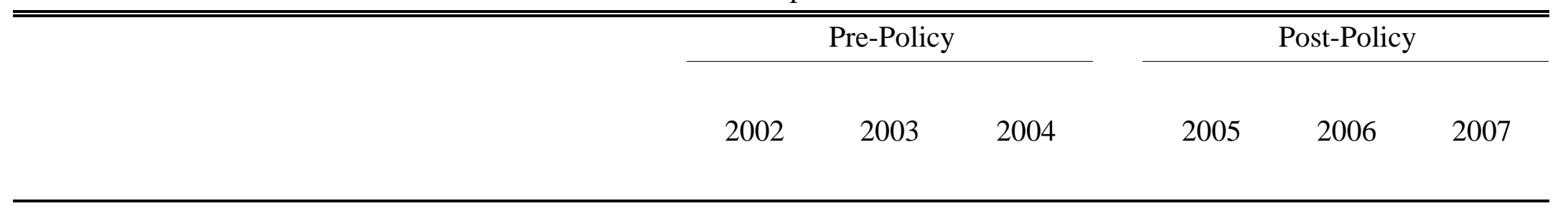

Teachers in year 1 (excluding temporary teachers)

$\begin{array}{lllllll}\text { Fraction who left the district next year } & 0.078 & 0.034 & 0.077 & 0.185 & 0.184 & 0.172 \\ \begin{array}{l}\text { Fraction who switched to another school within } \\ \text { the district next year }\end{array} & 0.009 & 0.014 & 0.051 & 0.109 & 0.102 & 0.109\end{array}$

Teachers in years 1-3 (excluding temporary teachers)

$\begin{array}{lllllll}\text { Fraction who left the district next year } & 0.087 & 0.062 & 0.098 & 0.172 & 0.169 & 0.160 \\ \begin{array}{l}\text { Fraction who switched to another school within } \\ \text { the district next year }\end{array} & 0.019 & 0.024 & 0.043 & 0.107 & 0.107 & 0.100\end{array}$

Teachers in years 5-15 (excluding temporary teachers)

\begin{tabular}{|c|c|c|c|c|c|c|}
\hline Fraction who left the district next year & 0.071 & 0.068 & 0.088 & 0.101 & 0.102 & 0.125 \\
\hline $\begin{array}{l}\text { Fraction who switched to another school within } \\
\text { the district next year }\end{array}$ & 0.058 & 0.043 & 0.049 & 0.066 & 0.066 & 0.073 \\
\hline
\end{tabular}


Table 3 - Summary Statistics for Analysis Sample

\begin{tabular}{|c|c|c|c|c|c|}
\hline & \multirow[b]{2}{*}{$\begin{array}{c}\text { All } \\
\text { Teachers }\end{array}$} & \multicolumn{2}{|c|}{ Pre-Policy (2003-2004) } & \multicolumn{2}{|c|}{ Post-Policy (2005-2008) } \\
\hline & & Untenured & Tenured & Untenured & Tenured \\
\hline & $(1)$ & $(2)$ & (3) & (4) & (5) \\
\hline \multicolumn{6}{|l|}{ Teacher Productivity } \\
\hline Number of absences & 8.760 & 9.459 & 8.898 & 8.207 & 8.781 \\
\hline At least 15 absences & 0.133 & 0.160 & 0.128 & 0.123 & 0.130 \\
\hline \multicolumn{6}{|l|}{ Teacher Characteristics } \\
\hline Male & 0.226 & 0.242 & 0.206 & 0.255 & 0.204 \\
\hline Black & 0.340 & 0.320 & 0.416 & 0.257 & 0.380 \\
\hline Hispanic & 0.142 & 0.167 & 0.097 & 0.172 & 0.127 \\
\hline White & 0.478 & 0.471 & 0.461 & 0.515 & 0.461 \\
\hline Age & 43.704 & 39.193 & 50.430 & 35.720 & 49.135 \\
\hline Years of experience & 12.344 & 7.591 & 19.095 & 4.916 & 17.453 \\
\hline Teaching in the same school last year & 0.190 & 0.278 & 0.067 & 0.341 & 0.084 \\
\hline MA+ & 0.499 & 0.329 & 0.595 & 0.399 & 0.617 \\
\hline Education Major & 0.502 & 0.405 & 0.606 & 0.378 & 0.599 \\
\hline College quality (1=lowest to $5=$ =highest) & 1.985 & 1.888 & 1.937 & 2.058 & 1.998 \\
\hline Failed at least one test & 0.157 & 0.210 & 0.068 & 0.223 & 0.118 \\
\hline Has not passed any tests & 0.264 & 0.175 & 0.521 & 0.069 & 0.346 \\
\hline \multicolumn{6}{|l|}{ School Characteristics } \\
\hline $\begin{array}{l}\text { Percent of students meeting national norms } \\
\text { or achieving proficiency }\end{array}$ & 0.477 & 0.398 & 0.423 & 0.485 & 0.531 \\
\hline Percent of students eligible for free lunch & 0.846 & 0.854 & 0.838 & 0.855 & 0.840 \\
\hline Percent of students who are Black & 0.485 & 0.510 & 0.492 & 0.498 & 0.460 \\
\hline Percent of students who are Hispanic & 0.377 & 0.370 & 0.366 & 0.373 & 0.389 \\
\hline Principal male & 0.377 & 0.376 & 0.375 & 0.378 & 0.379 \\
\hline Principal Black & 0.473 & 0.489 & 0.469 & 0.489 & 0.453 \\
\hline Principal White & 0.349 & 0.330 & 0.379 & 0.314 & 0.372 \\
\hline Principal Hispanic & 0.166 & 0.171 & 0.142 & 0.182 & 0.164 \\
\hline Principal age & 54.283 & 54.374 & 54.725 & 53.810 & 54.358 \\
\hline Principal B.A. in Education & 0.593 & 0.570 & 0.575 & 0.596 & 0.615 \\
\hline $\begin{array}{l}\text { Principal college quality (1=lowest to } \\
5=\text { highest) }\end{array}$ & 2.025 & 1.935 & 1.944 & 2.071 & 2.089 \\
\hline Number of teachers & 35,859 & 15,247 & 11,777 & 17,639 & 18,013 \\
\hline Number of teacher-year observations & 138,731 & 25,347 & 22,159 & 39,499 & 51,726 \\
\hline
\end{tabular}


Table 4 - The Impact of the Dismissal Policy on Teacher Absences

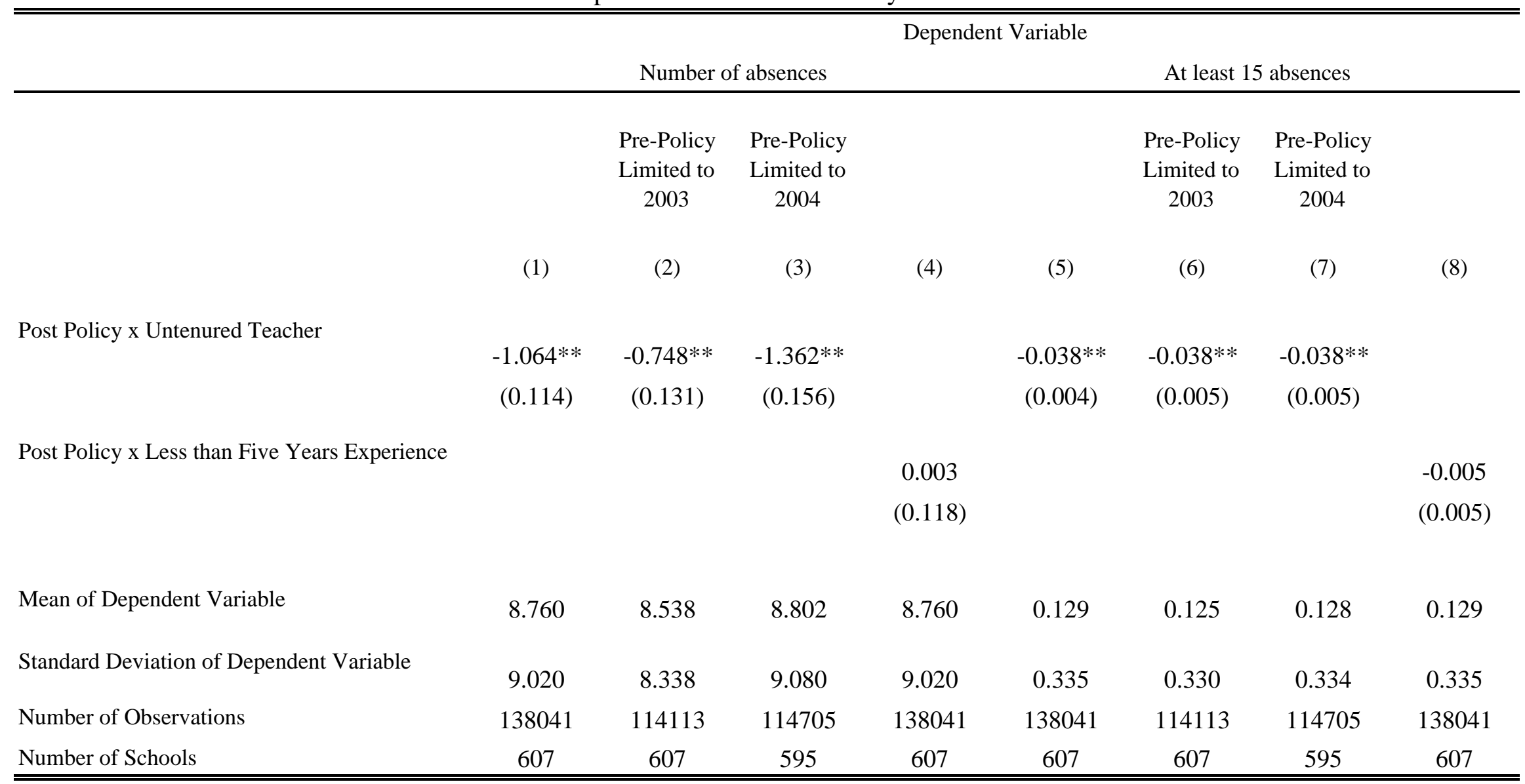

Notes: Each column represents a different regression. All regressions include a full set of fixed effects for school, years of teaching experience, and academic year. Standard errors clustered by school in parentheses. * significant at $10 \%$; ** significant at $5 \%$. 


\begin{tabular}{|c|c|c|c|c|}
\hline & & \multirow[b]{2}{*}{$\begin{array}{l}\text { Number of } \\
\text { Observations }\end{array}$} & \multicolumn{2}{|c|}{$\begin{array}{c}\text { Dependent Variable: Number } \\
\text { of Absences }\end{array}$} \\
\hline & & & $\begin{array}{l}\text { Mean (s.d.) of } \\
\text { Dependent } \\
\text { Variable }\end{array}$ & $\begin{array}{c}\text { Post Policy x } \\
\text { Untenured }\end{array}$ \\
\hline (1) & Baseline & 138041 & $\begin{array}{c}8.76 \\
(9.020)\end{array}$ & $\begin{array}{c}-1.064^{* *} \\
(0.114)\end{array}$ \\
\hline (2) & Dependent variable = sick days only & 138041 & $\begin{array}{c}6.467 \\
(6.434)\end{array}$ & $\begin{array}{c}-0.500^{* *} \\
(0.083)\end{array}$ \\
\hline (3) & Dependent variable $=$ personal days only & 138041 & $\begin{array}{c}1.3 \\
(1.318)\end{array}$ & $\begin{array}{c}-0.092^{* *} \\
(0.015)\end{array}$ \\
\hline (4) & Dependent variable $=$ other absences only & 138041 & $\begin{array}{c}0.993 \\
(5.175)\end{array}$ & $\begin{array}{c}-0.473^{* *} \\
(0.065)\end{array}$ \\
\hline (5) & Dependent variable $=$ total number of absences, excluding outliers $(>40)$ & 136129 & $\begin{array}{c}8.032 \\
(6.240)\end{array}$ & $\begin{array}{c}-0.603^{* *} \\
(0.078)\end{array}$ \\
\hline (6) & Dependent variable $=$ September-March absences & 138041 & $\begin{array}{c}5.751 \\
(7.029)\end{array}$ & $\begin{array}{l}-0.915^{* *} \\
(0.089)\end{array}$ \\
\hline (7) & Dependent variable $=$ April-June absences & 138041 & $\begin{array}{c}3.009 \\
(4.290)\end{array}$ & $\begin{array}{c}-0.149^{* *} \\
(0.052)\end{array}$ \\
\hline (8) & Only young tenured teachers in control group & 80762 & $\begin{array}{c}8.76 \\
(9.241)\end{array}$ & $\begin{array}{c}-0.664^{* *} \\
(0.214)\end{array}$ \\
\hline (9) & No school fixed effects & 138041 & $\begin{array}{c}8.76 \\
(9.020)\end{array}$ & $\begin{array}{c}-1.061^{* *} \\
(0.113)\end{array}$ \\
\hline (10) & Teacher and school demographics and no school fixed effects & 138041 & $\begin{array}{c}8.76 \\
(9.020)\end{array}$ & $\begin{array}{c}-1.083^{* *} \\
(0.114)\end{array}$ \\
\hline (11) & Teacher demographics with school fixed effects & 138041 & $\begin{array}{c}8.76 \\
(9.020)\end{array}$ & $\begin{array}{c}-1.061^{* *} \\
(0.114)\end{array}$ \\
\hline (12) & GLS, baseline specification (i.e., following Donald and Lang, 2007) & 138041 & $\begin{array}{c}8.76 \\
(9.020)\end{array}$ & $\begin{array}{c}-1.064^{* *} \\
(0.101)\end{array}$ \\
\hline & P-value based on 4 degrees of freedom & & & {$[0.000]$} \\
\hline (13) & Negative binomial (incidence-rate ratios) & 138041 & $\begin{array}{c}8.76 \\
(9.020)\end{array}$ & $\begin{array}{c}0.947 * * \\
(0.008)\end{array}$ \\
\hline (14) & Poisson (incidence-rate ratios) & 138041 & $\begin{array}{r}8.76 \\
(9.020) \\
\end{array}$ & $\begin{array}{l}0.895 * * \\
(0.003) \\
\end{array}$ \\
\hline
\end{tabular}

Notes: Each row represents a different regression. Regressions include school fixed effects, except where indicated otherwise. All regressions include a full set of fixed effects for academic year and years of teaching experience. Regressions with teacher demographics include race and gender dummies, race $\mathrm{x}$ gender interactions, teacher educational background controls, instructional program indicators, a cubic in age, and gender $\mathrm{x}$ age interactions. Regressions with school demographics include student race proportion variables, a cubic in school achievement, a cubic in school enrollment, an indicator for magnet schools, and an indicator for having multiple schools housed in the same building. Standard errors clustered by school in parentheses. * significant at $10 \%$; ** significant at $5 \%$. 
Table 6 - Composition versus Incentive Effects

\begin{tabular}{|c|c|c|c|c|c|c|c|c|c|c|c|}
\hline & & \multicolumn{10}{|c|}{ "Treatment group includes: } \\
\hline & & \multicolumn{2}{|c|}{ All untenured teachers } & \multicolumn{2}{|c|}{$\begin{array}{c}\text { Untenured teachers who } \\
\text { were temporarily assigned } \\
\text { to a position and not } \\
\text { necessarily fully certified }\end{array}$} & \multicolumn{2}{|c|}{$\begin{array}{c}\text { Untenured teachers who } \\
\text { were fully certified and } \\
\text { appointed to the tenure } \\
\text { track at the time of initial } \\
\text { hire }\end{array}$} & \multicolumn{2}{|c|}{$\begin{array}{l}\text { Untenured teachers who } \\
\text { were fully certified and } \\
\text { appointed to the tenure } \\
\text { track but only after } \\
\text { working for several years } \\
\text { in the district }\end{array}$} & \multicolumn{2}{|c|}{$\begin{array}{l}\text { Untenured teachers who } \\
\text { were fully certified but } \\
\text { not appointed to the } \\
\text { tenure track at the time } \\
\text { the new policy was } \\
\text { introduced }\end{array}$} \\
\hline & & $(1)$ & $(2)$ & (3) & $(4)$ & (5) & (6) & $(7)$ & (8) & (9) & $(10)$ \\
\hline & & School FE & Teacher FE & School FE & Teacher FE & School FE & Teacher FE & School FE & Teacher FE & School FE & Teacher FE \\
\hline (1) & Including all teachers & $\begin{array}{c}-1.06^{* *} \\
(0.11)\end{array}$ & $\begin{array}{c}0.17 \\
(0.13)\end{array}$ & & & & & & & & \\
\hline (2) & Including only teachers hired prior to the new policy & $\begin{array}{c}-1.02^{* *} \\
(0.13)\end{array}$ & $\begin{array}{c}0.15 \\
(0.13)\end{array}$ & $\begin{array}{c}-1.36 * * \\
(0.21)\end{array}$ & $\begin{array}{l}-0.15 \\
(0.22)\end{array}$ & $\begin{array}{c}0.12 \\
(0.17)\end{array}$ & $\begin{array}{c}0.13 \\
(0.18)\end{array}$ & $\begin{array}{c}0.27 \\
(0.22)\end{array}$ & $\begin{array}{c}0.54^{* *} \\
(0.24)\end{array}$ & $\begin{array}{c}-2.02 * * \\
(0.22)\end{array}$ & $\begin{array}{c}0.41 * \\
(0.21)\end{array}$ \\
\hline (3) & $\begin{array}{l}\text { Including only teachers hired prior to the new } \\
\text { policy, and excluding all observations from the } \\
\text { teachers who were ever fired and left the district }\end{array}$ & $\begin{array}{c}-1.26^{* *} \\
(0.13)\end{array}$ & $\begin{array}{l}-0.05 \\
(0.13)\end{array}$ & & & & & & & & \\
\hline & Mean of Dependent Variable & 9.048 & 9.048 & 8.933 & 8.933 & 8.681 & 8.681 & 8.987 & 8.987 & 9.012 & 9.012 \\
\hline & Standard Deviation of Dependent Variable & 9.256 & 9.256 & 8.945 & 8.945 & 8.635 & 8.635 & 8.984 & 8.984 & 9.355 & 9.355 \\
\hline & Number of Observations & 118399 & 118399 & 72972 & 72972 & 75342 & 75342 & 77225 & 77225 & 71180 & 71180 \\
\hline & Number of Treatment Teachers & 26447 & 26447 & 15853 & 15853 & 14959 & 14959 & 15325 & 15325 & 15752 & 15752 \\
\hline & Number of Schools & 607 & 607 & 607 & 607 & 605 & 605 & 605 & 605 & 606 & 606 \\
\hline
\end{tabular}

Notes: Each column represents a different regression. All regressions include a full set of fixed effects for years of teaching experience, and academic year. Standard errors clustered by school in parentheses. Mean (s.d.) of absences in row 1 is 8.76 (9.02) and for row 3 is 9.00 (9.18). The number of observations in rows 1 and 3 are 138,041 and 116,176 respectively. * significant at $10 \%$; ** significant at $5 \%$. 
Table 7 - Heterogeneity in the Effect of Teacher Dismissal on the Number of Teacher Absences

\begin{tabular}{|c|c|c|c|}
\hline & All untenured teachers & $\begin{array}{l}\text { Untenured teachers who } \\
\text { were temporarily assigned } \\
\text { to a position and not } \\
\text { necessarily fully certified }\end{array}$ & $\begin{array}{l}\text { Untenured teachers who } \\
\text { were fully certified and } \\
\text { appointed to the tenure } \\
\text { track at the time of initial } \\
\text { hire }\end{array}$ \\
\hline & (1) & $(2)$ & (3) \\
\hline \multirow[t]{2}{*}{ Post Policy x Untenured Teacher } & 0.192 & -0.004 & 0.267 \\
\hline & $(0.168)$ & $(0.271)$ & $(0.22)$ \\
\hline \multirow[t]{2}{*}{ Post Policy x Untenured Teacher x (Risk year 2) } & 0.03 & -0.064 & 0.156 \\
\hline & $(0.146)$ & $(0.227)$ & $(0.193)$ \\
\hline \multirow[t]{2}{*}{ Post Policy x Untenured Teacher x (Risk year 3 or more) } & -0.053 & -0.181 & -0.253 \\
\hline & $(0.215)$ & $(0.200)$ & $(0.301)$ \\
\hline \multirow[t]{2}{*}{ Untenured x 2006} & -0.302 & -0.066 & $-0.544^{* *}$ \\
\hline & $(0.198)$ & $(0.287)$ & $(0.250)$ \\
\hline \multirow[t]{2}{*}{ Untenured x 2007} & $-0.520 * *$ & -0.227 & $-0.729 * *$ \\
\hline & $(0.225)$ & $(0.326)$ & $(0.289)$ \\
\hline \multirow[t]{2}{*}{ Untenured x 2008} & $-0.440 *$ & -0.308 & $-0.624 *$ \\
\hline & $(0.253)$ & $(0.365)$ & $(0.329)$ \\
\hline \multirow[t]{2}{*}{ Fired in any prior year } & $-1.749 * *$ & $-2.322 * *$ & $-2.487 * *$ \\
\hline & $(0.22)$ & $(0.422)$ & $(0.351)$ \\
\hline
\end{tabular}

Notes: Each column represents a different regression. All regressions include a full set of fixed effects for teacher, years of teaching experience, and academic year. Standard errors clustered by school in parentheses. * significant at $10 \%$; $* *$ significant at $5 \%$. 
Table 8 - Impact of the Dismissal Policy on Teacher Absences by School Characteristics

\begin{tabular}{|c|c|c|c|c|c|c|c|c|c|}
\hline & All Schools & $\begin{array}{c}\text { Low Achieving } \\
\text { Schools }\end{array}$ & $\begin{array}{l}\text { High Achieving } \\
\text { Schools }\end{array}$ & $\begin{array}{l}\text { Mixed/ } \\
\text { Integrated } \\
\text { Schools }\end{array}$ & $\begin{array}{c}\text { Predom-inantly } \\
\text { Hispanic } \\
\text { Schools }\end{array}$ & $\begin{array}{l}\text { Predom-inantly } \\
\text { Black or } \\
\text { Minority } \\
\text { Schools }\end{array}$ & $\begin{array}{l}\text { Low Fraction } \\
\text { Probationary in } \\
2005\end{array}$ & $\begin{array}{c}\text { Medium } \\
\text { Fraction } \\
\text { Probationary in } \\
2005\end{array}$ & $\begin{array}{l}\text { High Fraction } \\
\text { Probationary in } \\
2005\end{array}$ \\
\hline & (1) & $(2)$ & (3) & (4) & (5) & (6) & (7) & (8) & (9) \\
\hline \multicolumn{10}{|l|}{ Panel A: Elementary Schools } \\
\hline Post Policy x Untenured Teacher & $\begin{array}{c}-1.300^{* *} \\
(0.135)\end{array}$ & $\begin{array}{c}-1.169 * * \\
(0.213)\end{array}$ & $\begin{array}{c}-1.432^{* *} \\
(0.174)\end{array}$ & $\begin{array}{c}-1.326^{* *} \\
(0.266)\end{array}$ & $\begin{array}{c}-1.278^{* *} \\
(0.296)\end{array}$ & $\begin{array}{c}-1.359 * * \\
(0.190)\end{array}$ & $\begin{array}{c}-1.372^{* *} \\
(0.260)\end{array}$ & $\begin{array}{c}-1.311^{* *} \\
(0.238)\end{array}$ & $\begin{array}{c}-1.329 * * \\
(0.216)\end{array}$ \\
\hline Mean of Dependent Variable & 8.817 & 9.476 & 8.29 & 8.073 & 8.309 & 9.407 & 8.878 & 8.842 & 8.737 \\
\hline Standard Deviation of Dependent Variable & 9.378 & 9.748 & 9.051 & 9.055 & 8.783 & 9.738 & 9.502 & 9.37 & 9.234 \\
\hline Number of Observations & 97788 & 43778 & 53306 & 25510 & 21579 & 50699 & 30962 & 34996 & 31392 \\
\hline Number of Schools & 488 & 239 & 240 & 131 & 94 & 315 & 159 & 159 & 159 \\
\hline \multicolumn{10}{|l|}{ Panel B: High Schools } \\
\hline Post Policy x Untenured Teacher & $\begin{array}{c}-0.525^{* *} \\
(0.204)\end{array}$ & $\begin{array}{l}-0.621 \\
(0.382)\end{array}$ & $\begin{array}{c}-0.528 * * \\
(0.238)\end{array}$ & $\begin{array}{l}-0.286 \\
(0.231)\end{array}$ & $\begin{array}{c}0.751 \\
(0.594)\end{array}$ & $\begin{array}{c}-0.837 * * \\
(0.298)\end{array}$ & $\begin{array}{c}-0.578 * * \\
(0.250)\end{array}$ & $\begin{array}{l}-0.387 \\
(0.339)\end{array}$ & $\begin{array}{l}-0.654 \\
(0.573)\end{array}$ \\
\hline Mean of Dependent Variable & 8.624 & 9.524 & 8.287 & 7.917 & 7.995 & 9.06 & 8.542 & 8.526 & 9.151 \\
\hline Standard Deviation of Dependent Variable & 8.083 & 8.936 & 7.71 & 7.378 & 7.654 & 8.442 & 8.083 & 7.91 & 8.528 \\
\hline Number of Observations & 40253 & 11930 & 27274 & 13059 & 2468 & 24726 & 16269 & 17070 & 6292 \\
\hline Number of Schools & 119 & 50 & 53 & 24 & 7 & 97 & 34 & 34 & 35 \\
\hline
\end{tabular}

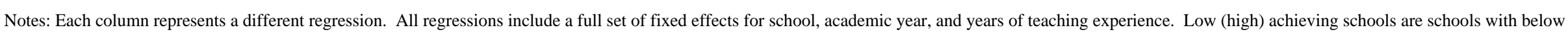

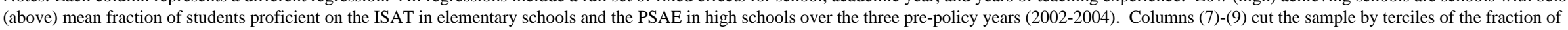
probationary teachers in the school in 2005 . Standard errors clustered by school in parentheses. * significant at $10 \%$; ${ }^{* *}$ significant at $5 \%$. 
Table 9 - Impact of the Dismissal Policy on Teacher Absences by Teacher Characteristics

\begin{tabular}{|c|c|c|c|c|c|c|c|c|c|c|c|}
\hline & $\begin{array}{c}\text { All } \\
\text { Teachers }\end{array}$ & Male & Female & White & Black & Hispanic & Over 35 & Under 35 & $\begin{array}{c}\text { Low } \\
\text { Predicted } \\
\text { Absences }\end{array}$ & $\begin{array}{l}\text { Moderate } \\
\text { Predicted } \\
\text { Absences }\end{array}$ & $\begin{array}{c}\text { High } \\
\text { Predicted } \\
\text { Absences }\end{array}$ \\
\hline & (1) & (2) & (3) & (4) & (5) & (6) & (7) & (8) & (9) & $(10)$ & (11) \\
\hline \multicolumn{12}{|l|}{ Panel A: Elementary Schools } \\
\hline Post Policy x Untenured Teacher & $\begin{array}{c}-1.300^{* *} \\
(0.135)\end{array}$ & $\begin{array}{c}-0.877^{* *} \\
(0.340)\end{array}$ & $\begin{array}{c}-1.367 * * \\
(0.151)\end{array}$ & $\begin{array}{c}-1.227^{* *} \\
(0.197)\end{array}$ & $\begin{array}{c}-1.290 * * \\
(0.244)\end{array}$ & $\begin{array}{c}-1.460 * * \\
(0.327)\end{array}$ & $\begin{array}{c}-1.724^{* *} \\
(0.190)\end{array}$ & $\begin{array}{c}0.236 \\
(0.436)\end{array}$ & $\begin{array}{c}-0.553 * * \\
(0.238)\end{array}$ & $\begin{array}{c}-1.157^{* *} \\
(0.248)\end{array}$ & $\begin{array}{c}-0.868 * * \\
(0.283)\end{array}$ \\
\hline Mean of Dependent Variable & 8.817 & 8.149 & 8.936 & 8.421 & 9.649 & 8.489 & 8.879 & 8.679 & 7.924 & 8.888 & 9.646 \\
\hline Standard Deviation of Dependent Variable & 9.378 & 8.849 & 9.466 & 9.169 & 9.867 & 8.79 & 9.233 & 9.688 & 8.066 & 9.349 & 10.495 \\
\hline Number of Observations & 97788 & 14881 & 82907 & 45208 & 33196 & 15861 & 67209 & 30579 & 32705 & 32677 & 32406 \\
\hline \multicolumn{12}{|l|}{ Panel B: High Schools } \\
\hline Post Policy x Untenured Teacher & $\begin{array}{c}-0.525^{* *} \\
(0.204)\end{array}$ & $\begin{array}{l}-0.153 \\
(0.278)\end{array}$ & $\begin{array}{c}-0.778 * * \\
(0.255)\end{array}$ & $\begin{array}{l}-0.299 \\
(0.273)\end{array}$ & $\begin{array}{c}-0.697 * * \\
(0.326)\end{array}$ & $\begin{array}{c}-0.13 \\
(0.754)\end{array}$ & $\begin{array}{c}-0.592^{* *} \\
(0.255)\end{array}$ & $\begin{array}{c}0.73 \\
(0.679)\end{array}$ & $\begin{array}{c}0.276 \\
(0.297)\end{array}$ & $\begin{array}{c}-0.17 \\
(0.313)\end{array}$ & $\begin{array}{c}-1.443^{* *} \\
(0.441)\end{array}$ \\
\hline Mean of Dependent Variable & 8.624 & 7.933 & 9.093 & 8.086 & 9.61 & 8.882 & 8.732 & 8.392 & 7.497 & 8.768 & 9.611 \\
\hline Standard Deviation of Dependent Variable & 8.083 & 7.772 & 8.255 & 7.729 & 8.672 & 7.946 & 8.287 & 7.618 & 7.077 & 8.132 & 8.809 \\
\hline Number of Observations & 40253 & 16287 & 23966 & 20737 & 13757 & 3801 & 27502 & 12751 & 13447 & 13427 & 13379 \\
\hline
\end{tabular}

Notes: Each column represents a different regression. All regressions include a full set of fixed effects for school, academic year, and years of teaching experience. Predicted absences in columns (9)-(11) are estimated from a regression using only pre-policy observations including teacher, school, and principal demographics. Standard errors clustered by school in parentheses. * significant at $10 \%$; ** significant at $5 \%$. 
Table 10 - Impact of the Dismissal Policy on School Level Student Achievemen

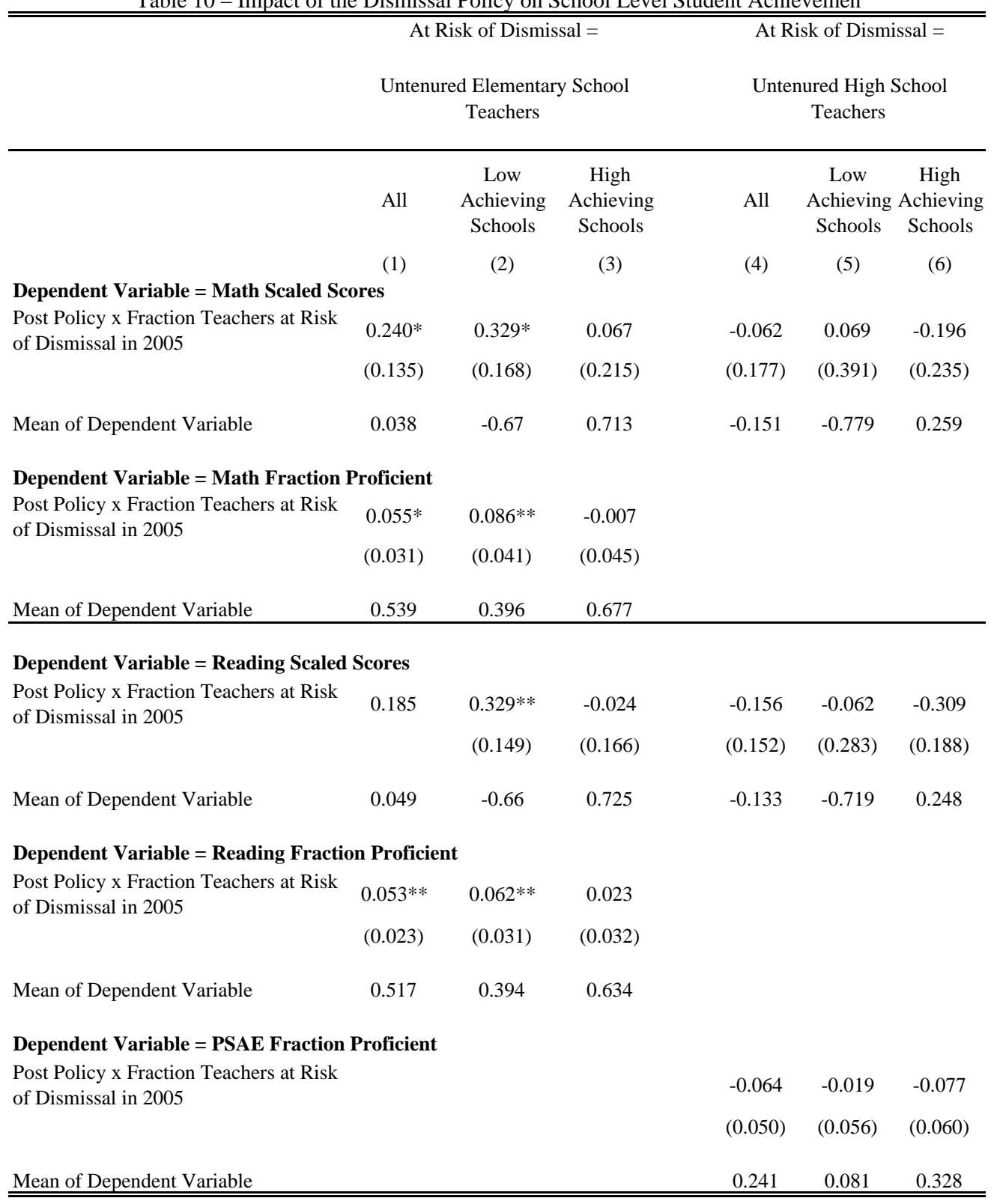

Notes: Each cell represents a different school-year level regression with the indicated dependent variable. Standard errors clustered by school in parentheses. The elementary school assessment is the math and reading ISAT taken in grades 3,5 , and 8 . Scaled scores are standardized at the school level within grade-subject-year to a mean of 0 and a standard deviation of 1 . All assessment outcomes represent an enrollment weighted average across grades within sche year. All regressions include controls for the fraction of low income students in the school year, fraction of low income students x post policy, mean level of teaching experience in the school-year, mean experience squared, the fraction of first or second year teachers in the school-year, other school demographics, indicators for whether the assessment is observed in each grade, the fraction of enrolled students in the grade taking the exam, and a full set of fixed effects for school and academic year. Low (high) achieving schools are schools with below (above) mean fraction of students proficient on the ISAT/PSAE over the three pre-policy years (2002-2004). For elementary schools, the mean within school percent probationary (untenured) teachers in 2005 was 33\% (43\%), the 96 percentile was 50\% (65\%) and the $10^{\text {th }}$ percentile was $19 \%(26 \%)$. The high school scaled score assessments are the EXPLORE, PLAN and ACT exams taken in grades 9, 10 and 11, respectively. The high school fraction proficient assessment is the PSAE. For high schools, the mean within school percent probationary (untenured) teachers in 2005 was $40 \%$ (52\%), the 90th percentile was $58 \%(74 \%)$ and the 10 th percentile was $30 \%(37 \%)$. ${ }^{*}$ significant at $10 \%$; ** significant at $5 \%$. 